$$
\begin{gathered}
\text { U.s.Army } \\
\text { Coast.Eng. Res. } \\
\text { Ctr. } \\
\text { MP 4.75 } \\
\text { (AD-AOIO } 348 \text { ) }
\end{gathered}
$$

\title{
Concept Analysis :
}

\section{Offshore Breakwater-Oil Storage System}

\author{
by
}

Joseph Peraino and Tomasz Plodowski

\section{MISCELLANEOUS PAPER NO. 4-75 \\ APRIL 1975}
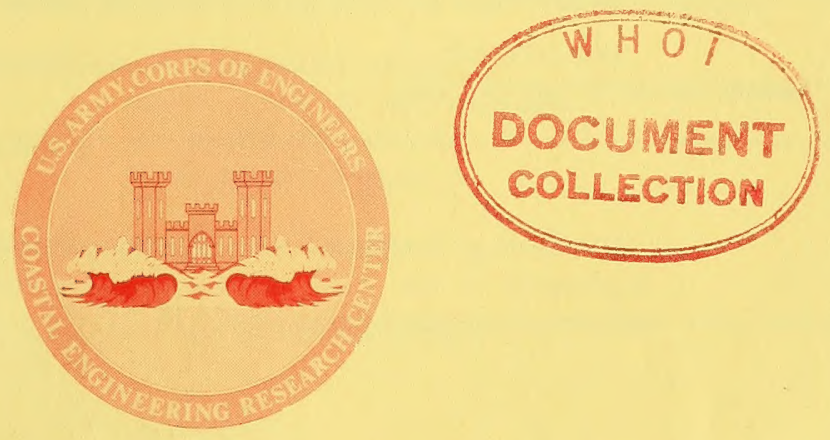
Approved for public release; distribution unlimited

Prepared for

\section{U. S. ARMY, CORPS OF ENGINEERS}

\section{$G B \rightarrow$ COASTAL ENGINEERING 450 \\ .43 \\ RESEARCH CENTER}

no. 4-75

Kingman Building

Fort Belvoir, Va. 22060 
Reprint or republication of any of this material shall give appropriate credit to the U.S. Army Coastal Engineering Research Center.

Limited free distribution within the United States of single copies of this publication has been made by this Center. Additional copies are available from:

\author{
National Technical Information Service \\ ATTN: Operations Division \\ 5285 Port Royal Road \\ Springfield, Virginia 22151
}

The findings in this report are not to be construed as an official Department of the Army position unless so designated by other authorized documents.

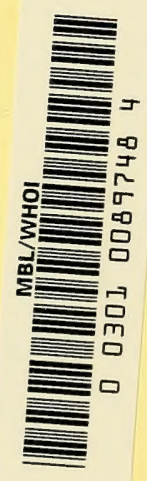




\section{REPORT DOCUMENTATION PAGE}

1. REPORT NIIMBER

4. TITLE (and Subtitle)

CONCEPT ANALYSIS: OFFSHORE BREAKWATEROIL STORAGE SYSTEM

Miscellaneous Paper

6. PERFORMING ORG. REPORT NUMBER

8. CONTRACT OR GRANT NUMBER(a)

DACW72-73-C-0005

Tomasz P1odowski

9. PERFORMING ORGANIZATION NAME AND ADDRESS

Raymond Technical Facilities Inc.

Two Pennsylvania Plaza

New York, New York 10001

11. CONTROLLING OFFICE NAME AND ADDRESS

Department of the Army

Coastal Engineering Research Center (CEREN-DE)

Kingman Building, Fort Belvoir, Virginia 22060

14. MONITORING AGENCY NAME \& ADDRESS(If different from Controlling Office)
10. PROGRAM ELEMENT, PROJECT, TASK AREA \& WORK UNIT NUMBERS

B31234

12. REPORT DATE

April 1975

13. NUMBER OF PAGES

15. SECURITY CLASS. (of this report)

Unclassified

15a. DECLASSIFICATION/DOWNGRADING

16. DISTRIBUTION STATEMENT (of this Report)

Approved for public release; distribution unlimited

17. DISTRIBUTION STATEMENT (of the abstract enfered in Block 20, if different from Report)

18. SUPPLEMENTARY NOTES

19. KEY WORDS (Continue on reverse side if necessary and tdentify by block number)

Concept Analysis

offshore Breakwater
Oil Storage System

Precast Floating Units

20. ABSTRACT (Continue an reverse side it necosaary and identify by block number)

This study attempts to arrive at a satisfactory method of providing a prompt and efficient answer to the fast-growing need for deep-draft berthing facilities along the U.S. east coast. The general concept of large hollow precast floating units towed to the site, and sunk into position lends itself particularly to using the hollow interiors as storage space for liquid bulk cargo in large quantities. Since the trend for more economical transportation of petroleum products is by use of large deep-draft carriers, the 


\section{Abstract (Continued)}

combination breakwater-oil storage system is a possible solution.

Assumptions were made as to probable site conditions, i.e., water depths, sea conditions, bottom conditions, and a preliminary design developed for the units. Various construction procedures were studied and compared from both technical and construction cost aspects. Once all technical advantages and disadvantages had been considered, the most suitable design was completed, a construction procedure laid out, and a basic budget estimate prepared.

With this basic estimate, it was possible, with a series of factors, to adjust this basic cost to other water depths and other loçations.

Design principles, construction procedures and cost estimates are detailed in the report, including basic assumptions, sample design calculations, and estimate breakdown. 


\section{PREFACE}

This report is published to assist coastal engineers in investigating the feasibility of designing and constructing a deepwater port for an offshore breakwater-oil storage system. The work was carried out under the coastal construction research program of the U.S. Army Coastal Engineering Research Center.

This report was prepared by Raymond Technical Facilities, Inc., under CERC Contract No. DACW72-73-C-0005. Cost estimates used in this study are based on market prices for December 1972; any proposed construction must include inflation increases.

The authors, Joseph Peraino and Tomasz Plodowski, gratefully acknowledge the generous assistance and encouragement provided by CERC personnel during preparation of this study.

Dr. J. Richard Weggel was the CERC contract monitor for the report, under the general supervision of Mr. Robert A. Jachowski, Chief, Design Branch, and Mr. George M. Watts, Chief, Engineering Development Division.

Comments on this publication are invited.

Approved for publication in accordance with Pub1ic Law 166, 79th Congress, approved 31 July 1945, as supplemented by Public Law 172 , 88 th Congress, approved 7 November 1963.

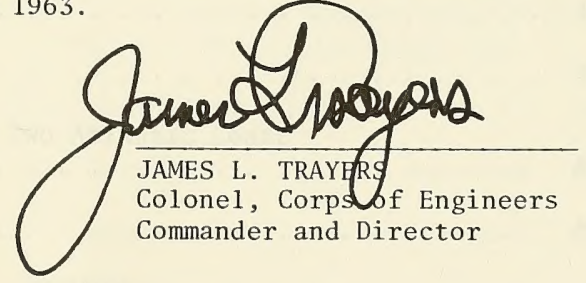


I INTRODUCTION ............................ . . . . . 9

1. Nature and Purpose of Study . . . . . . . . . . . . 9

2. Background . . . . . . . . . . . . . . . 10

II DESIGN CONSIDERATIONS . . . . . . . . . . . . . . . 10

1. Study Conditions . . . . . . . . . . . . . . . 10

2. Selection of Design Wave . . . . . . . . . . . . . . 11

3. Effect of Perforated Exterior Wall . . . . . . . . . 12

4. Calculations . . . . . . . . . . . . . 13

5. Review of Results . . . . . . . . . . . . . . 13

III CONSTRUCTION METHODS . . . . . . . . . . . . . . . . 16

1. Previous Work . . . . . . . . . . . . . . . . 16

2. Overa11 Program . . . . . . . . . . . . . 18

3. Detailed Operations . . . . . . . . . . . . . 31

IV CONSTRUCTION COSTS . . . . . . . . . . . . . . . . . . 41

1. Comments and Assumptions . . . . . . . . . . . . . 41

2. Cost Estimates and Cost Curves . . . . . . . . . . 46

$\mathrm{V}$ CONCLUSIONS . . . . . . . . . . . . . . . . . . 47

LITERATURE CITED . . . . . . . . . . . . . . . . . . 54

APPENDIX - Sample Calculations for Design of
Concrete Caisson . . . . . . . . . . . . . 55

TABLES

1 Construction Schedule . . . . . . . . . . . . . . 42

2 Estimated Basic Cost . . . . . . . . . . . . . . 46

3 Modified Estimated Cost for Two Atlantic Coast Locations . . . . . . . . . . . . . . . . . 47

4 Estimate Details . . . . . . . . . . . . . . . 49

FIGURES

Frontispiece - Offshore Breakwater-0il Storage System . . . . . . 8

1 Cellular concrete caisson for 100-foot water depth . . . . . 14

2 Precast concrete breakwater for 110- to 50-foot water depths ..................... . . 15 
3 Water depth versus concrete volume . . . . . . . . . . 17

4 Water depth versus minimum draft of floating caisson . . . . 17

5 Offshore construction areas . . . . . . . . . . . . 19

6 Annual percent exceedance of wave height Boston, Massachusetts . . . . . . . . . . . . . 21

7 Annual percent exceedance of wave height Atlantic City, New Jersey . . . . . . . . . . . . . . 22

8 Annual percent exceedance of wave height Norfolk, Virginia . . . . . . . . . . . . . . . 23

9 Annual percent exceedance of wave height -

Cape Hatteras, North Carolina . . . . . . . . . . . . . 24

10 Monthly percent exceedance of wave height Boston, Massachusetts . . . . . . . . . . . . . 25

11 Monthly percent exceedance of wave height Atlantic City, New Jersey . . . . . . . . . . . . . 26

12 Monthly percent exceedance of wave height Norfolk, Virginia . . . . . . . . . . . . . . . 27

13 Monthly percent exceedance of wave height -

Cape Hatteras, North Carolina . . . . . . . . . . . . . 28

14 Percent frequency wave height - New York Harbor . . . . . . 29

15 Wave rose . . . . . . . . . . . . . . . . . 30

16 Onshore caisson casting area . . . . . . . . . . . . . 32

17 Plan of screeding procedure . . . . . . . . . . . . . 34

18 Screeding procedure - Elevation . . . . . . . . . . . 35

19 Screeding procedure - Section . . . . . . . . . . . 36

20 Construction method - Alternate screeding procedure . . . . 38 


\section{CONTENTS}

\section{FIGURES - Continued}

21 Setting precast concrete breakwater units . . . . . . . . 40

22 Cost curves . . . . . . . . . . . . . . 4 48 


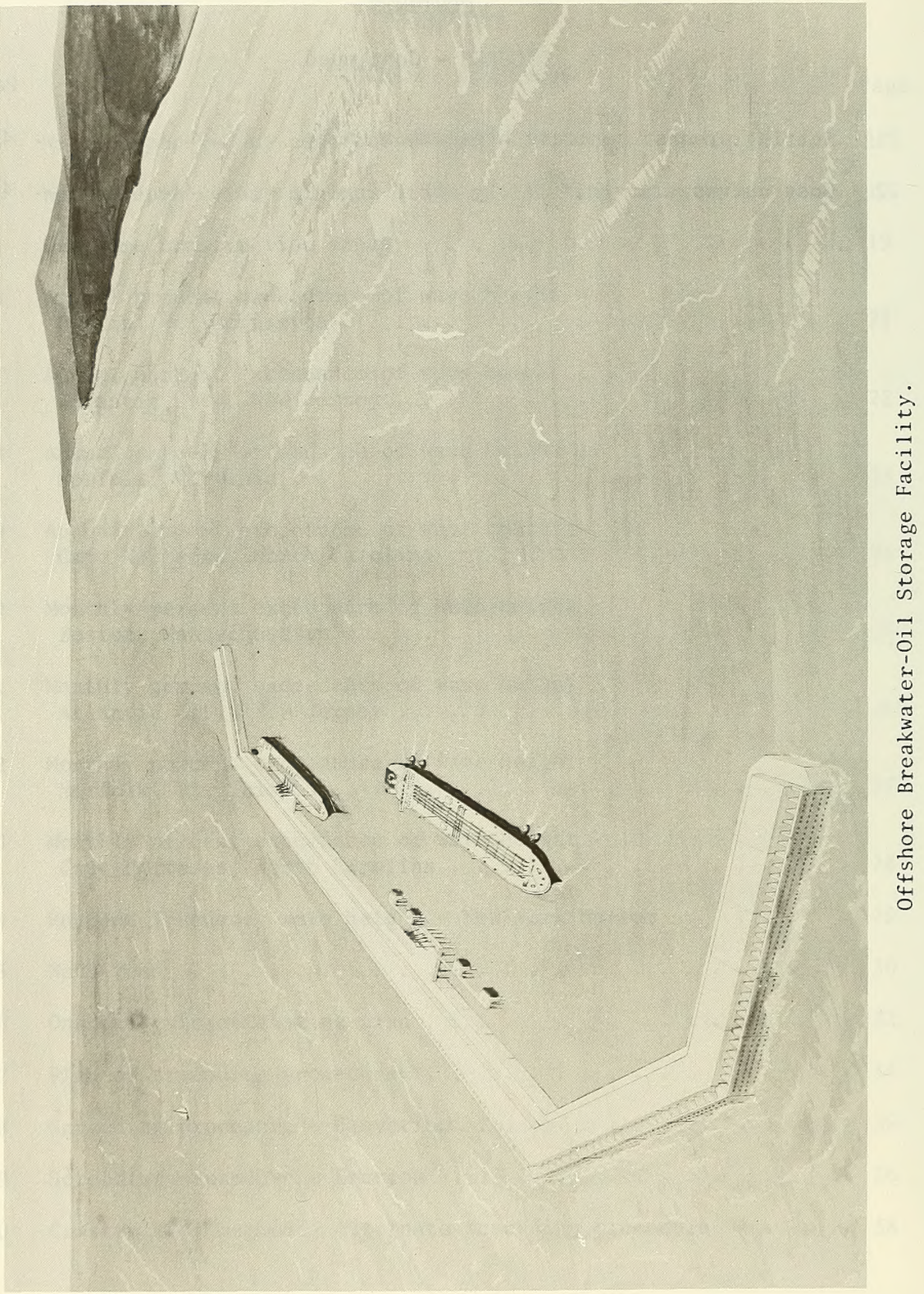




$$
\begin{gathered}
\text { by } \\
\text { Joseph Peraino and Tomasz PLodowski }
\end{gathered}
$$

\section{INTRODUCTION}

1. Nature and Purpose of Study.

This study developed from the urgency for establishment of a deepwater port along the U.S. east coast, primarily to ease the physical difficulties and cost of importing petroleum products in the vastly increasing quantities necessary now and in the immediate future. The principal purpose of the report, therefore, was to investigate the feasibility of designing and constructing a deepwater port conceived along the following lines.

The basic concept of a combination breakwater-oil storage system could provide an advantageous approach. In this concept, the port is composed of several precast box units, constructed in deepwater facilities close inshore, towed to the site, sunk in position, and connected to afford a sheltered berthing area on the leeward side. With the inner and outer compartmentation of these box units, a protected storage facility is provided by the interior compartments; the exterior compartments provide necessary protection from collision damage and accidental spil1.

The size of the units, the perforated wall of the outer compartment (effectively reducing the force of approaching waves on the structure), as well as their location and general arrangement will afford protection and maximum possible berth availability under extreme weather conditions. Storage and berthing capacity are practically limitless, depending only on the number of units in the layout.

Within this basic concept, the study consisted of (a) establishing design criteria by assuming probable site conditions, (b) comparing construction procedures, (c) arriving at the most suitable design concept, and (d) developing that concept by a preliminary design in enough detail to prepare a budget estimate. Variations can be prepared for comparison of construction costs in various water depths at different localities from this basic design and estimate.

Some further economic advantages of the offshore storage location which have not been developed here, but should be given careful consideration in any final analysis are:

(a) Drastic reduction in number of unloading operations involving supertankers as compared with smaller tankers presently in use. 
(b) Comparatively high-berth availability, reducing waiting time for large tankers.

(c) Need for only small pipelines to shore, because of the onsite provision of temporary storage.

(d) Possibility of auxiliary uses.

(e) Relatively low shoreside impact.

2. Background.

The concept of prefabricated units floated to the site and sunk into position is not new, although it has been gaining popularity.

Prefabricated units are a particularly popular concept of breakwater construction in the Mediterranean area, e.g., for a seawall and breakwater at the port of Genoa, Italy, and for oil terminals at Gela, Sicily, and at Marsa E1 Brega near Benghazi, Libya. The concept has also been adapted to the design and construction of other marine structures such as bridge piers, water intakes, and tunnels built by the trench method.

Unit construction was used to a limited extent during World War II under combat conditions off the invasion beaches of Normandy. With the prime requisites being simplicity, speed of placement with minimal onsite construction operations and adequate serviceability although for a comparatively short time, the units served their purpose well, and within design limits.

The concept of outer perforations to reduce the force of approaching waves has been incorporated into the breakwater at Baie Comeau, Quebec, and the deepwater concrete storage tank structure for the Ekofisk Field in the North Sea.

\section{DESIGN CONSIDERATIONS}

1. Study Conditions.

To incorporate some facts and figures into the study, assumptions were made and basic physical conditions established as reasonable design conditions.

The site was assumed to be off the U.S. east coast and exposed to severe wave action. It was located on a compact sandy bottom deep enough to keep channel dredging at a minimum for deep-draft carriers. Not only is dredging minimized, but also the associated problems of spoil disposal.

The assumed location would not be greatly affected by tidal currents, and if present, would normally be of small velocity. More important, the site can be chosen so as not to interfere with established traffic 
routes and to avoid any serious navigation hazards or obstructions.

For the basic system, it was assumed that protected berthing for two 500,000 deadweight ton-supertankers, and offshore storage facility for 10 million barrels of oil were to be provided. These conditions dictate a location in 110-foot depth, and a minimum breakwater length of 8,600 feet.

Other inherent advantages which should not be overlooked, in line with the basic concept, are:

(a) Prefabrication is easier under yard conditions in a protected coastal area. This leaves only a few difficult onsite operations.

(b) Use of massive gravity-type units will eliminate the need for special anchorage systems to maintain location on the final site.

(c) This construction is suitable for the use of reinforced concrete, particularly for permanent structures in an open sea environment, and with a high resistance to the abrasive and corrosive action at such a location.

(d) The general scheme of oil storage being confined to the interior compartments of the structure provides an almost leak-proof system. Protection for these compartments against ship collision damage from the seaward side is provided by both the wave chamber and the grout-filled crash barrier; and from the harbor side, by the sand-filled exterior compartment. As an added precaution, lining the inside of all exterior sides of the storage compartments with light steel plate or plastic will guard against seepage through these surfaces.

2. Selection of Design Wave.

Since the study was not made for a particular location, the design significant wave height was taken as 32.1 feet, which gives maximum wave height equal to $1.87 \times 32.1=60$ feet.

The 60-foot wave was selected from storm data in the Atlantic region and other data using hindcasting methods to obtain wave characteristics.

The maximum water surface elevation (astronomical tide plus storm surge) was assumed to be 10.0 feet.

The wave period used to proportion the structure was selected as an average of the periods obtained using two approaches: 
(a) For $\mathrm{H}_{S}=32.1$ feet and $\mathrm{U}=100$ knots, $\mathrm{T}_{S}=11.8$ seconds. This corresponds to a fetch length of 39 nautical miles and a minimum duration of 100-knot winds of 2.7 hours.

(b) For $H_{S}=32.1$ feet and a fetch of 1,000 nautical miles, $\mathrm{T}_{S}=16.8$ seconds. This relates to $\mathrm{U}=39$ knots and a minimum duration of 39-knot winds of 52 hours.

Therefore, the wave period used to proportion the structure was:

$$
\mathrm{T}_{S}=\frac{11.8+16.8}{2}=14.3 \text { seconds }
$$

In addition, safety factors were evaluated for the 11.8- and 16.8-second conditions to determine the sensitivity of the stmucture's stability to variations on wave period.

3. Effect of Perforated Exterior Wa11.

The breakwater is made of concrete caissons of cellular construction with a perforated front wall and wave chamber.

The seaward perforated vertical wall reduces wave forces exerted on the structure by dissipating a part of the wave energy within the wave chamber and at the perforations.

The perforated wall decreases reflection and thus lowers the crest of the standing wave (clapotis). The front wall perforations also reduce scour at the toe of the caisson.

Since the original concept of a perforated breakwater was developed by Jarlan in 1965 , other works have been published on the subject (Coastal Engineering Research Center, 1966; Marks and Jarlan, 1968). The most informative report used in this study of the effect of the wave forces on a perforated breakwater was by Marks and Jarlan (1968).

Marks and Jarlan state that the energy dissipated at a vertical perforated structure is about 65 percent of the total energy of the incident wave. This corresponds to the relationship,

$$
\frac{\left(\mathrm{H}_{2}\right)^{2}}{\left(\mathrm{H}_{1}\right)^{2}}=(1-0.65)=0.35
$$

where $\mathrm{H}_{1}$ is the height of the wave approaching the structure, and $\mathrm{H}_{2}$ is the equivalent wave height at the structure.

Because of the nature of this study and the wave properties being considered, the perforated breakwater may not be as effective as Marks 
and Jarlan (1968) suggest. Because of this, the following relationship was used:

$$
\frac{\left(\mathrm{H}_{2}\right)^{2}}{\left(\mathrm{H}_{1}\right)^{2}}=0.64
$$

This gives $\mathrm{H}_{2}=0.8 \mathrm{H}_{1}$.

The general Sainflou method was then used to compute the wave forces on the structure (Jarlan, 1961).

A reduction factor for wave pressure can be applied when computing resultant forces on a breakwater section 250 feet long or longer, because the maximum pressure occurs at the same time only over comparatively small structure lengths for the irregular wind waves experienced during hurricanes. However, for the present study, no reduction factor has been applied.

\section{Calculations.}

Sample calculations for the concrete caisson in 110-foot water depth are given in the Appendix. Dimensional details of the caisson are shown in Figure 1.

The concrete units were proportioned for water depths ranging from 50 to 110 feet, both with and without oil storage capabilities.

The results of these studies are shown in Figure 2 .

\section{Review of Results.}

The analysis shows that the units required for the oil storage and nonoil storage alternatives in either 90 - or 110 -foot water depths are basically the same size regardless of depth. The size is dictated by the required safety factor against sliding and on allowable soil-bearing pressures.

The design wave force determines the minimum weight and base width of the unit. The width required for stability provides enough space for oil storage compartments. The units can be designed to provide additional oil storage.

Increasing the base width above the minimum width established by the force exerted by the design wave will in effect reduce the soil pressure and increase the safety factor.

For installations where units are to function primarily as a breakwater without oil storage, the leeward face can be perforated to reduce reflected wave action within the harbor. However, when the units are 


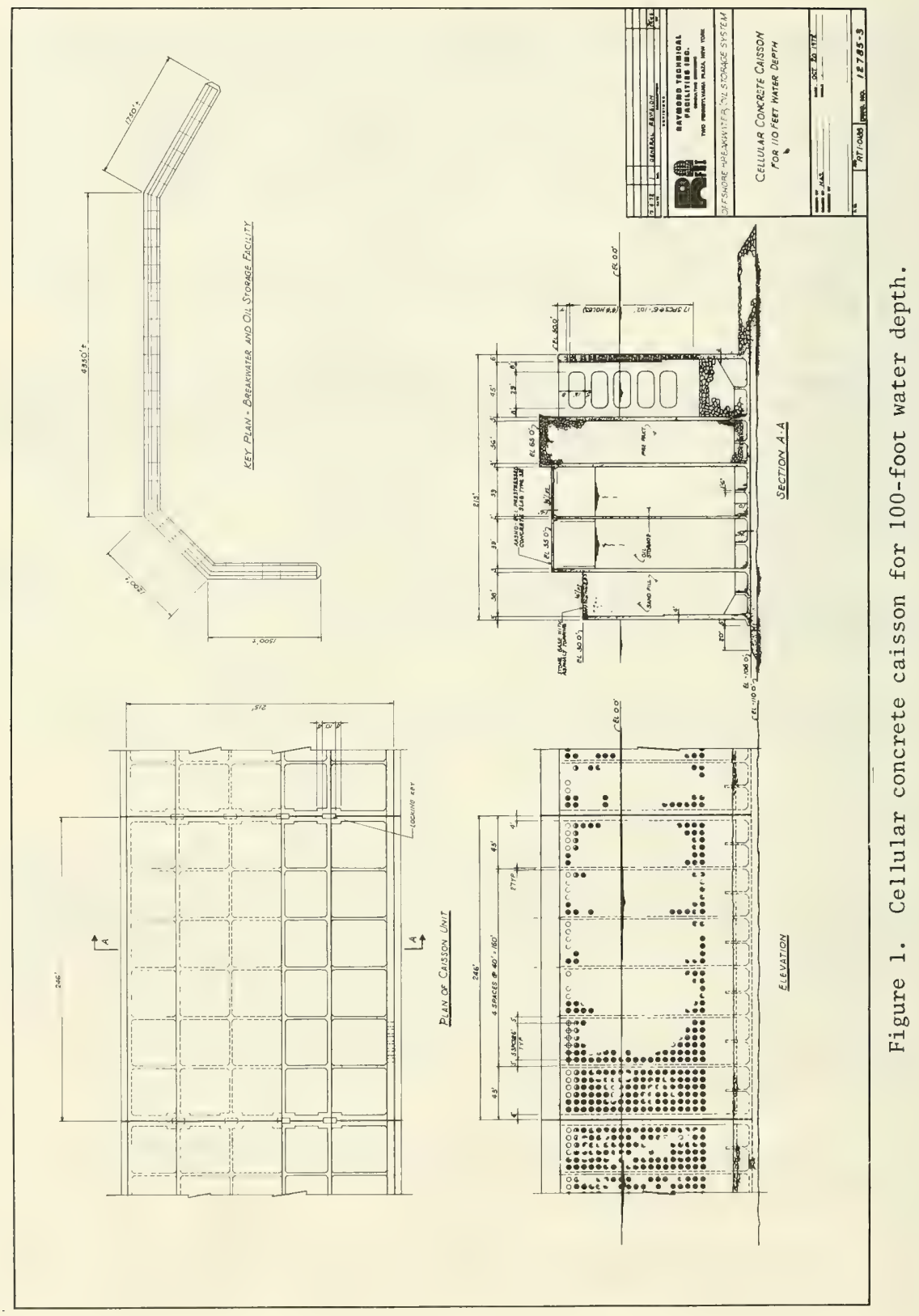




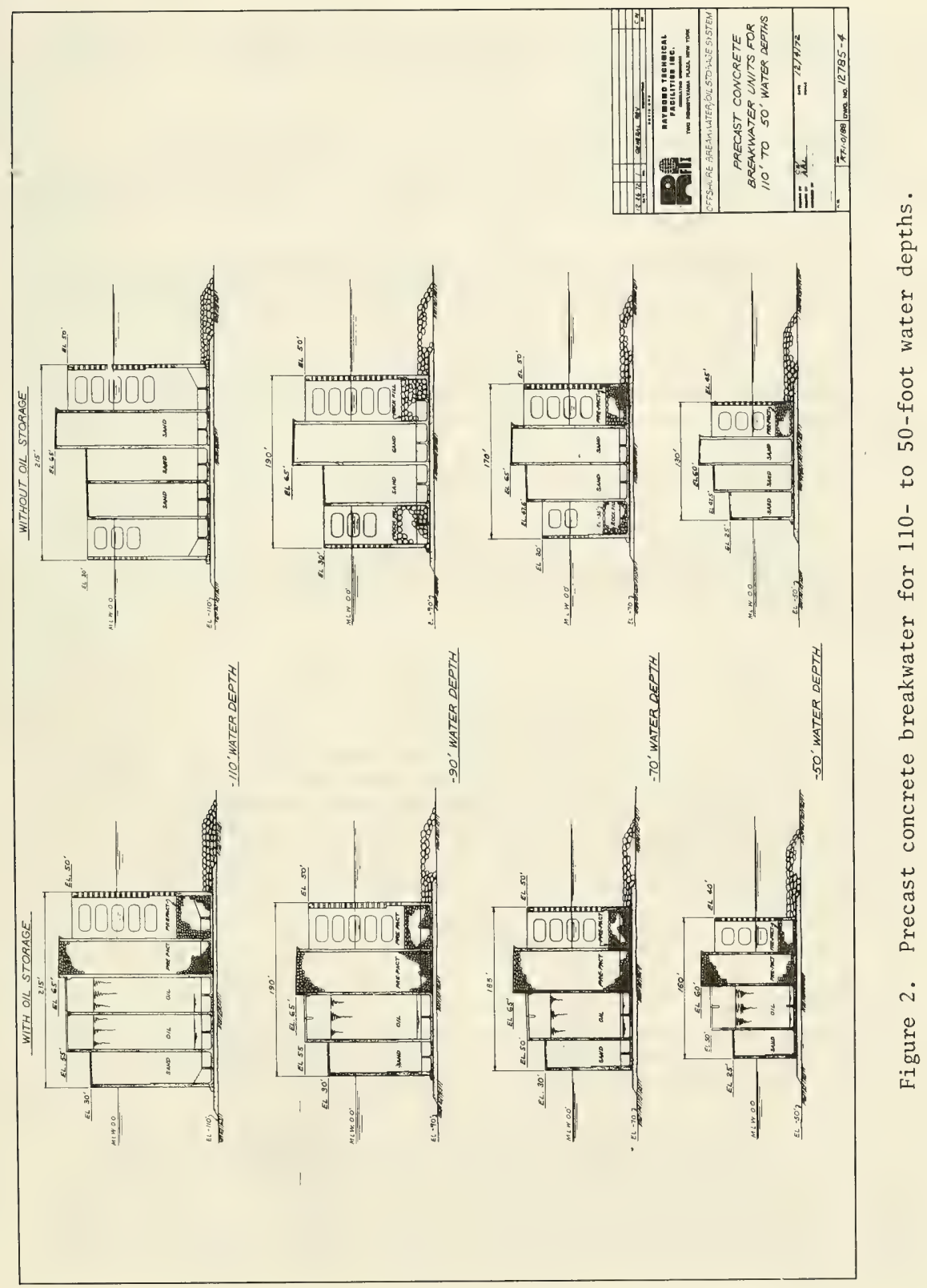


being used for oil storage, an extra compartment to provide perforations on the leeward side may not be justified. This would depend on economic and physical conditions at each specific site.

The sizes of the units required for 50 - to 70-foot depths are different for the oil storage and nonoil storage alternatives. If a significant amount of oil storage is required, an increase in the overall size of the units is necessary.

The extra compartment needed to incorporate perforations on the leeward face of the units does not seem justified for this range of water depths, unless exceptionally quiet conditions within the harbor is essential.

The preceding results are shown in Figure 2, and certain implications of these results on concrete volumes and draft requirements are shown in Figures 3 and 4 .

In summary, as indicated in the calculations of the Appendix:

(a) The critical condition (maximum force on the structure) can be estimated from the equivalent static load obtained from maximum wave conditions, by using the Sainflou equation along with a wave height reduction factor due to the perforated breakwater.

(b) Since the structure is rigid, the dynamic response due to wave forces can be assumed negligible.

(c) Maximum wave forces are greater than earthquake forces. Since both earthquake forces and maximum wave forces will seldom occur simultaneously, the maximum wave force was used for design. A wave of 37.5 feet acting simultaneously with earthquake forces will give a force equivalent to that of the maximum design of 60 feet combined with earthquake force will still result in a safety factor of 1.4, rather than the safety factor of 2 used in the design.

\section{CONSTRUCTION METHODS}

\section{Previous Work.}

In recent years, construction requirements and construction capabilities have pushed each other forward. The work contemplated here falls well within the construction industry's capabilities.

Offshore platforms for varied uses of the oil industry have been constructed all over the world. With depths ranging from relatively shallow water to over 300 feet, platforms have been constructed using free-standing piling connected only by the platform deck itself, braced templates with piles driven through the legs, and sunken caissons, some floated out and sunk directly, and some floated on the side and upended for sinking. 


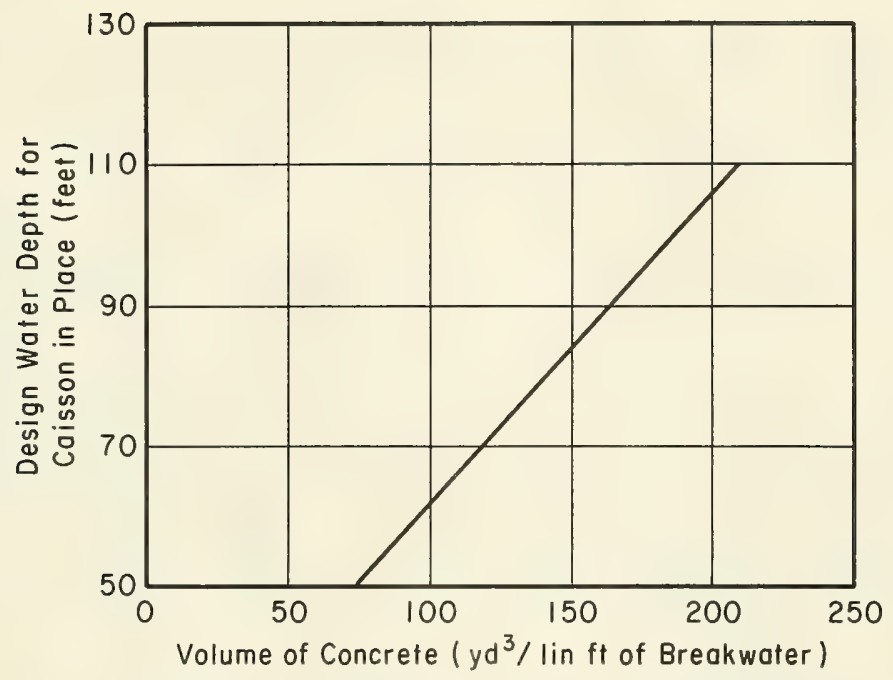

Figure 3. Water depth versis concrete volume.

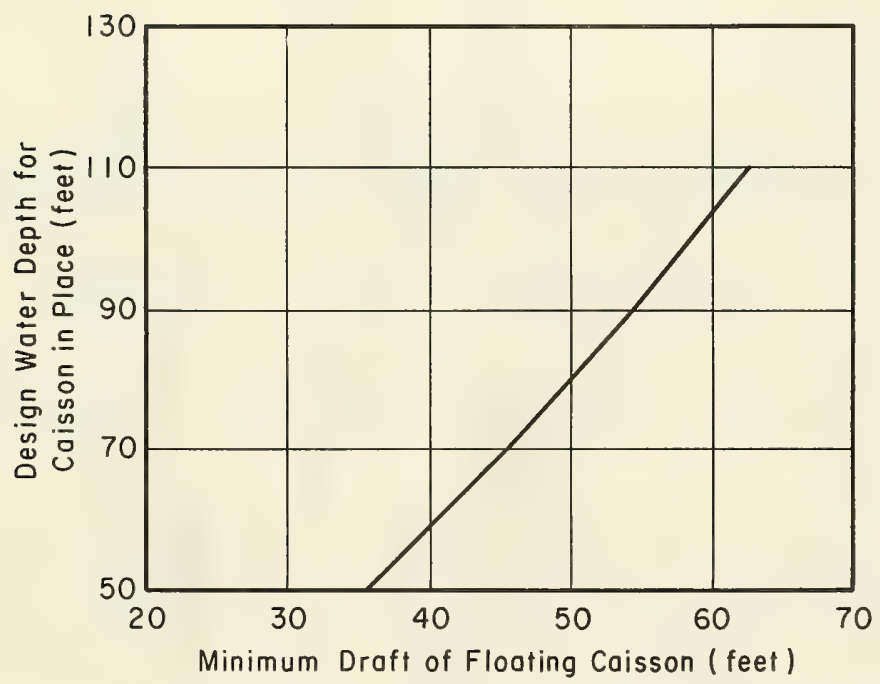

Figure 4. Water depth versus minimum draft of floating caisson. 
Other structures for navigation purposes and for close inshore breakwater and pier facilities have successfully used similar principles in their construction. Caisson foundations used for bridge construction are also similar, but are often basically open-bottomed and sunk by excavation through the unit itself.

The laying of tube sections in a dredged trench with subsequent backfilling is becoming more popular in tunnel construction. Tunnel sections are prefabricated onshore with sealed ends, towed to location, sunk, connected to the previously laid part, and then covered and finished.

While none of the above techniques exactly reproduce the technique proposed by this study, the concept of fabricating large units onshore or in a drydock, outfitting at a protected pier site, towing to location in open water and sinking into place as shown in Figure 5, are routine constmction procedures. Certain adaptations are always necessary to allow for particular draft requirements, such as onsite bottom conditions and connection and anchoring needs, but these present no real problem to presently available construction techniques.

Mode1 studies recommended for the design phase of the work may be helpful in developing or adapting major construction techniques and construction equipment. Possibly, the same model tests conducted for the design studies, with some slight modification, can be used to provide additional data for the efficient design and use of construction equipment.

\section{Overal1 Program.}

The construction program is based on established procedures we 11 proven on earlier projects. Because work is being done under similar conditions in the open sea, and considering the current capability and ingenuity of the construction industry, provision for the operations necessary for this study represents development of present practice. Therefore, an efficient and economical construction scheme can be laid out for the project under study.

In planning the construction phase to establish an offshore breakwater-oil storage system, various possible construction procedures were carefully considered.

Once the general design was determined, specific requirements dictated by flotation characteristics, towing and positioning methods, preparation of prefabrication sites and final installation site, were carefully reviewed before proceeding to a final design. These factors influenced the final design, and formed the basis for estimated construction schedules and costs.

Factors considered in this area of the study are: 


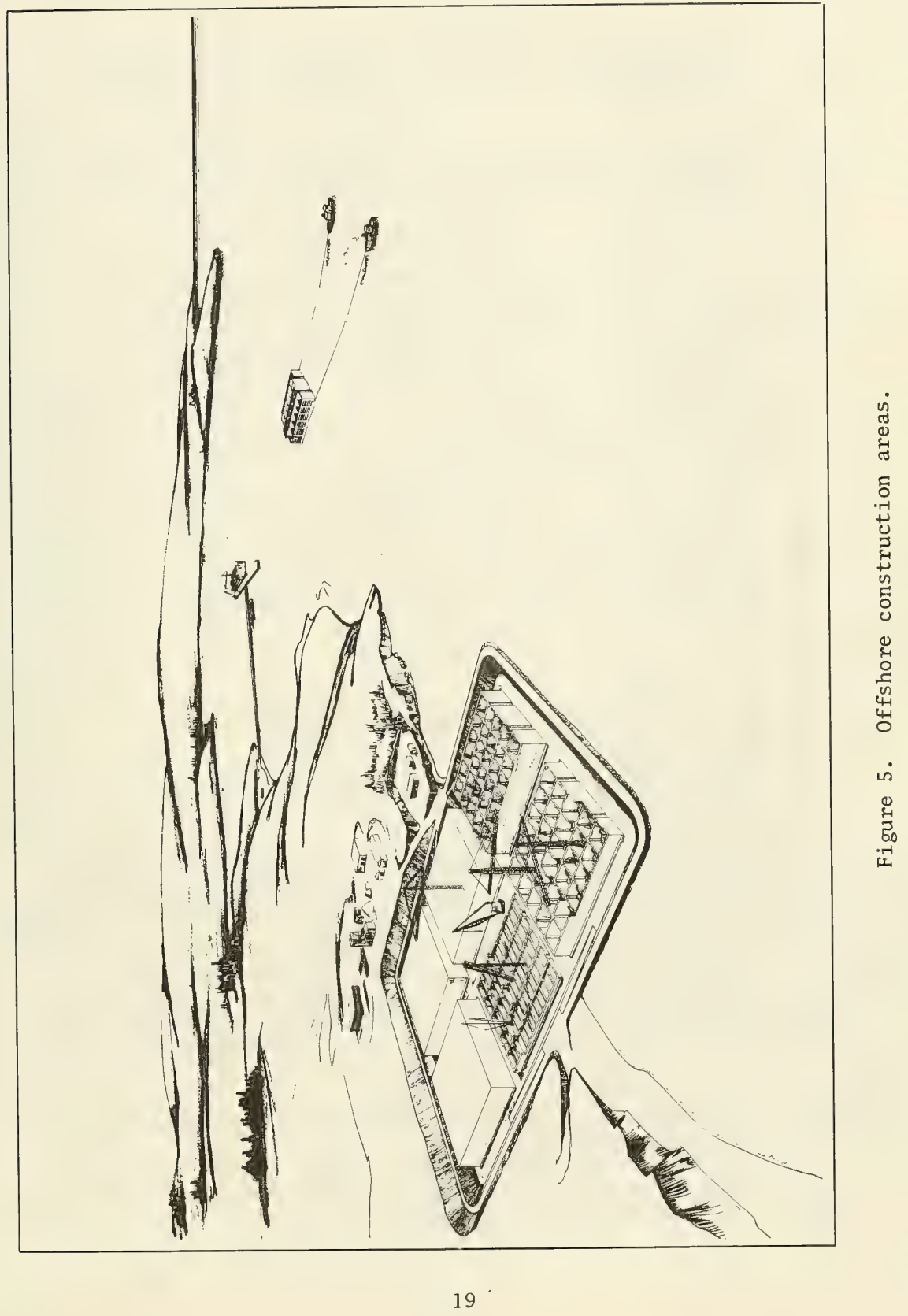


(a) Lower leve1 concrete pours.

(1) Geographical location of casting sites in relation to installation site.

(2) Use of established facilities (shipyards, drydocks) versus facilities specifically setup for the project.

(b) Upper leve1 pours and fitting out.

(1) Location of available deepwater sites and accessibility to the installation site by natural channels.

(2) Necessity of dredging basins or channels.

(c) Transportation of units.

(1) Flotation and stability.

(2) Location of towing points and mooring gear.

(d) Placing of units at installation site. available.

(1) Necessary site preparation and equipment

(2) Source of stone.

(3) Operation sequence from moving unit to site, to positioning, and sinking.

(e) Weather and sea conditions, and their effect on items (a) through (d).

Studies of weather and sea conditions (Savi11e, 1954; U.S. Naval Weather Service Command, 1970) were used to estimate conditions to be expected during construction. An indication of wave heights and frequency both annually and monthly for various locations along the U.S. east coast are given in Figures 6 through 14. Figure 15 provides wave heights as a function of percentage of occurrence from various directions. The data were particularly useful at this stage in developing construction time and delay costs for the estimate, both at the site and along the towing routes.

Based on the foregoing, a construction program was planned that included the following operations:

(a) Establishment of a dike-enclosed basin for construction of lower parts of the caisson units. 


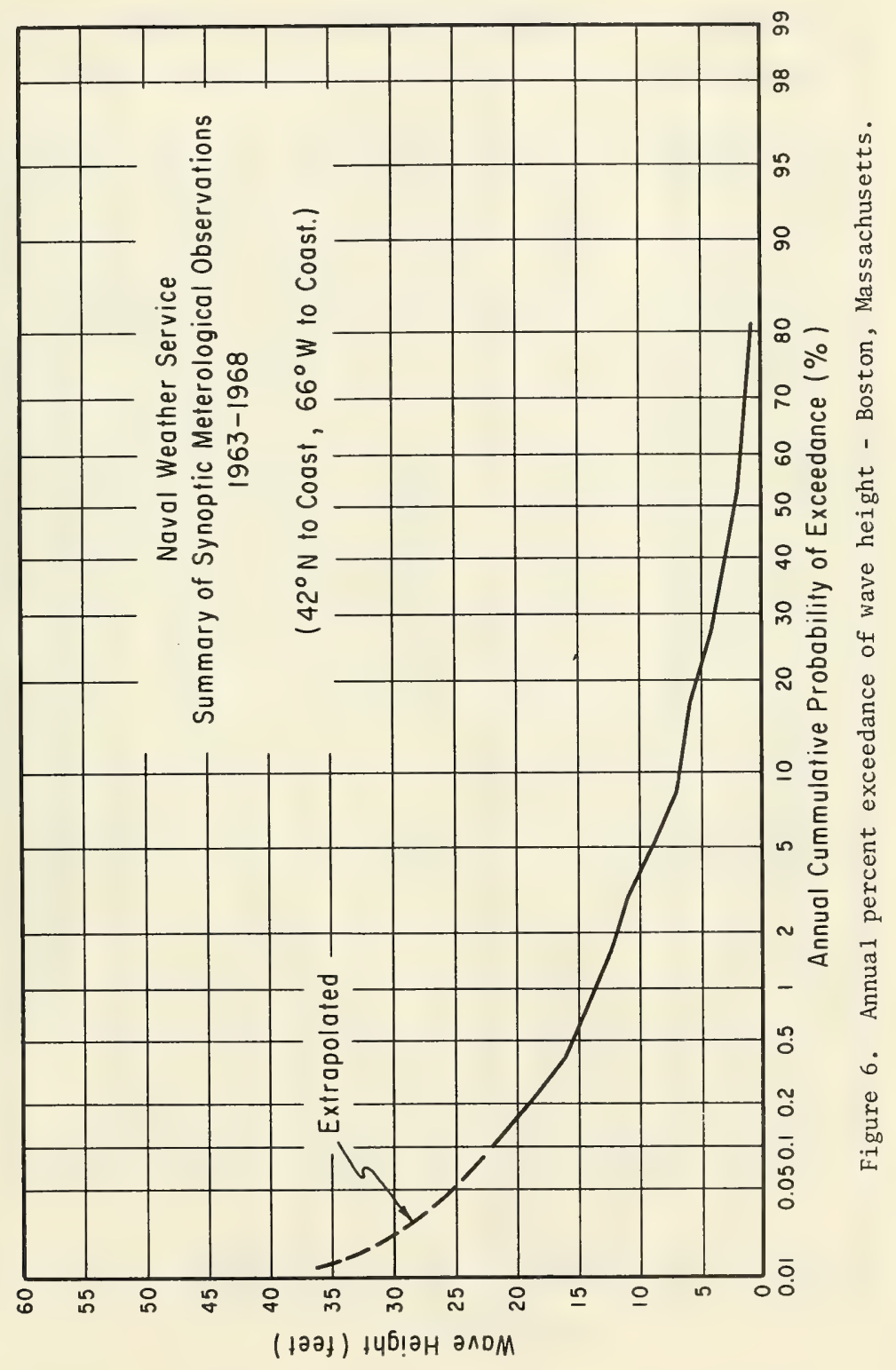




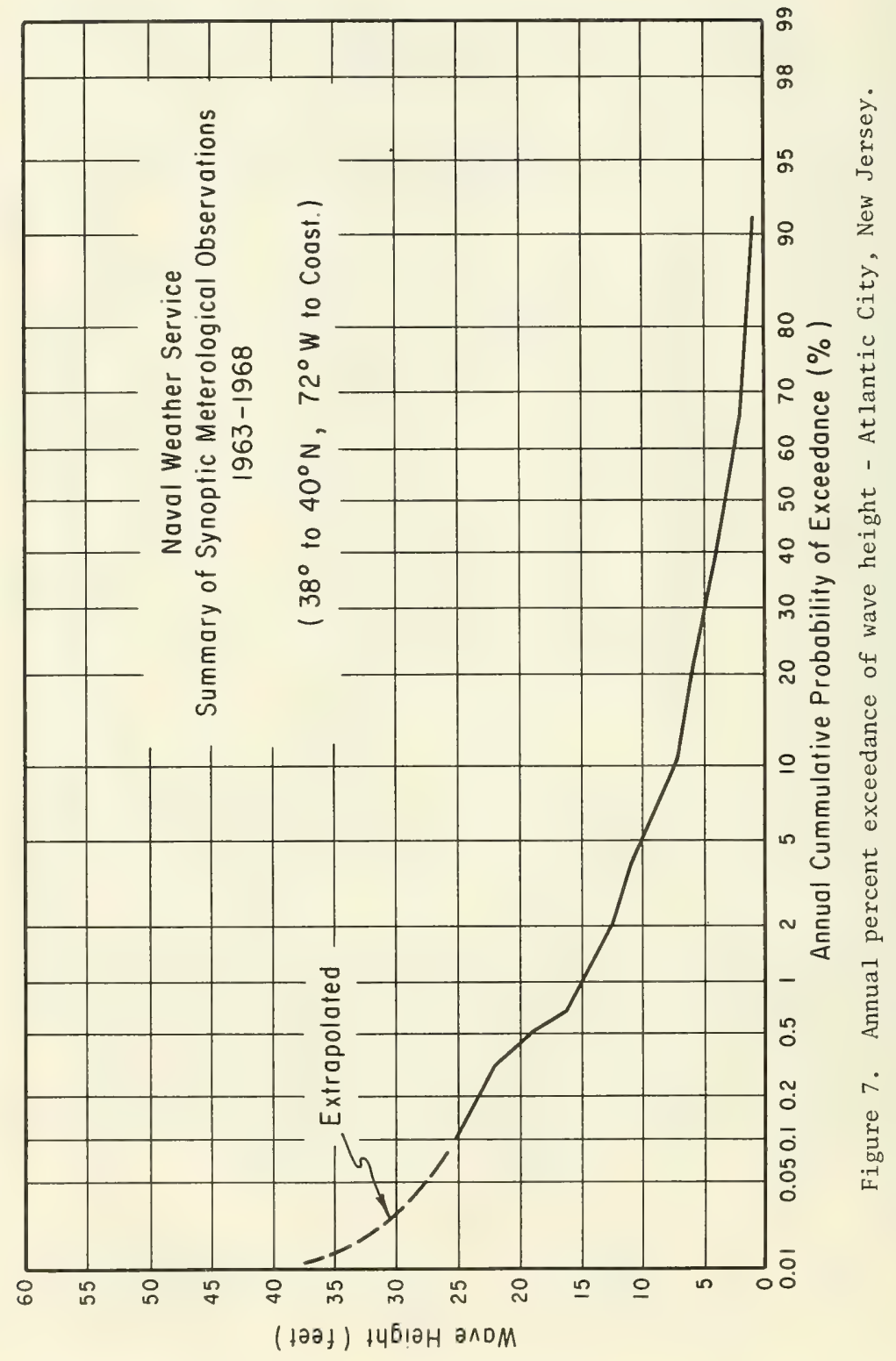




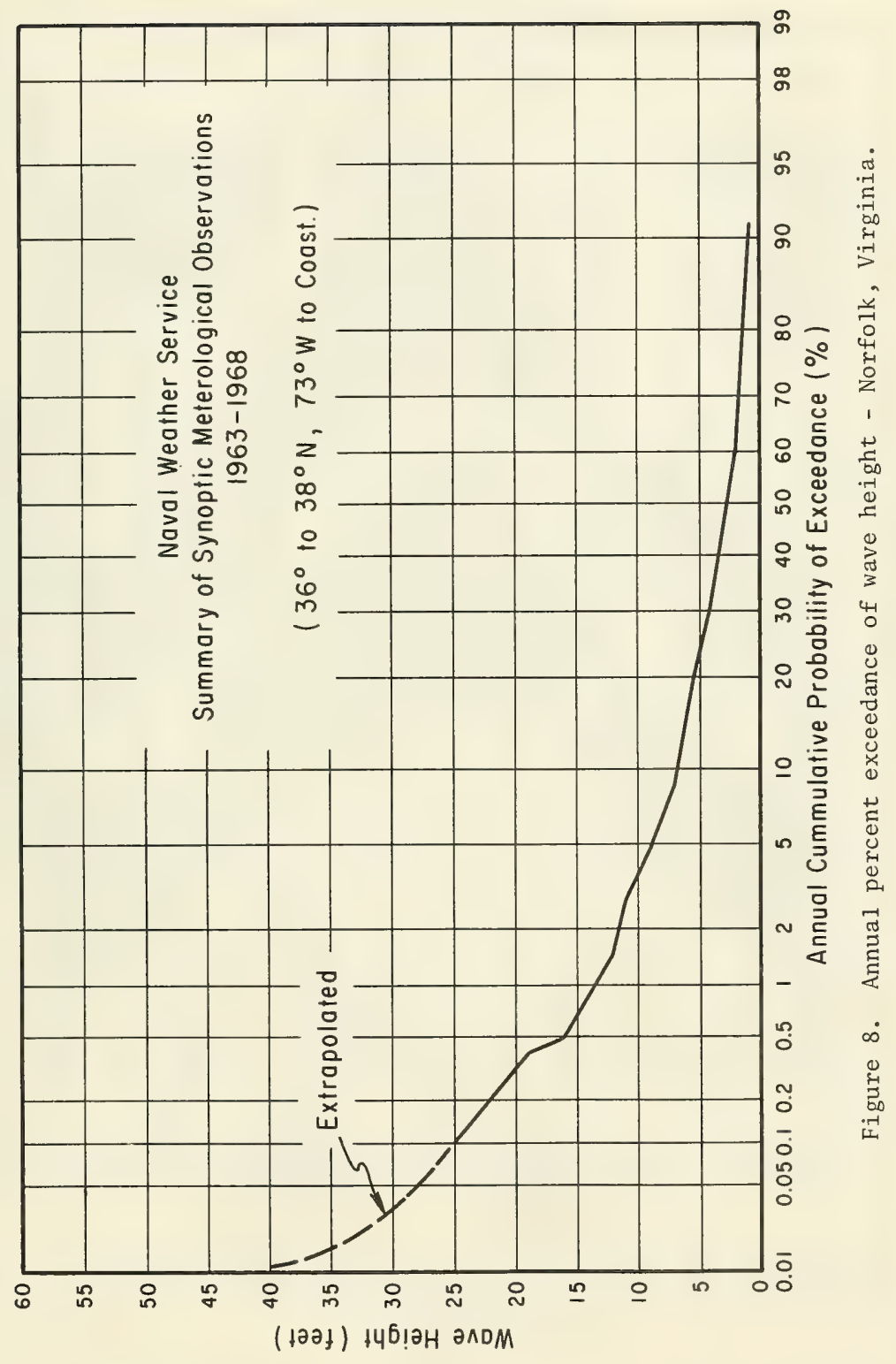




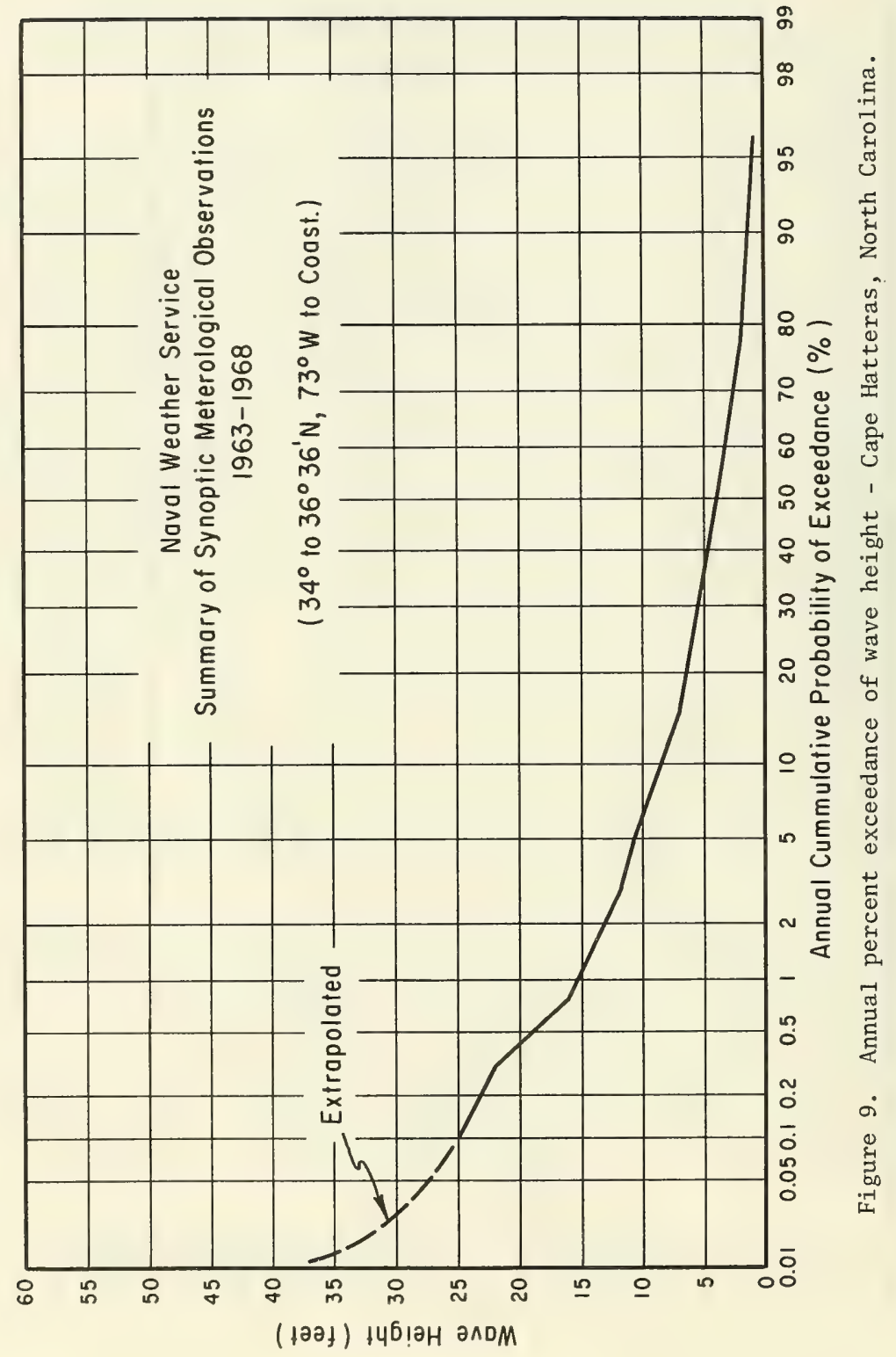


Naval Weather Service

Summary of Synoptic Meterological Observations

$1963-1968$

( $42^{\circ} \mathrm{N}$ to Coast, $66^{\circ} \mathrm{W}$ to Coost)

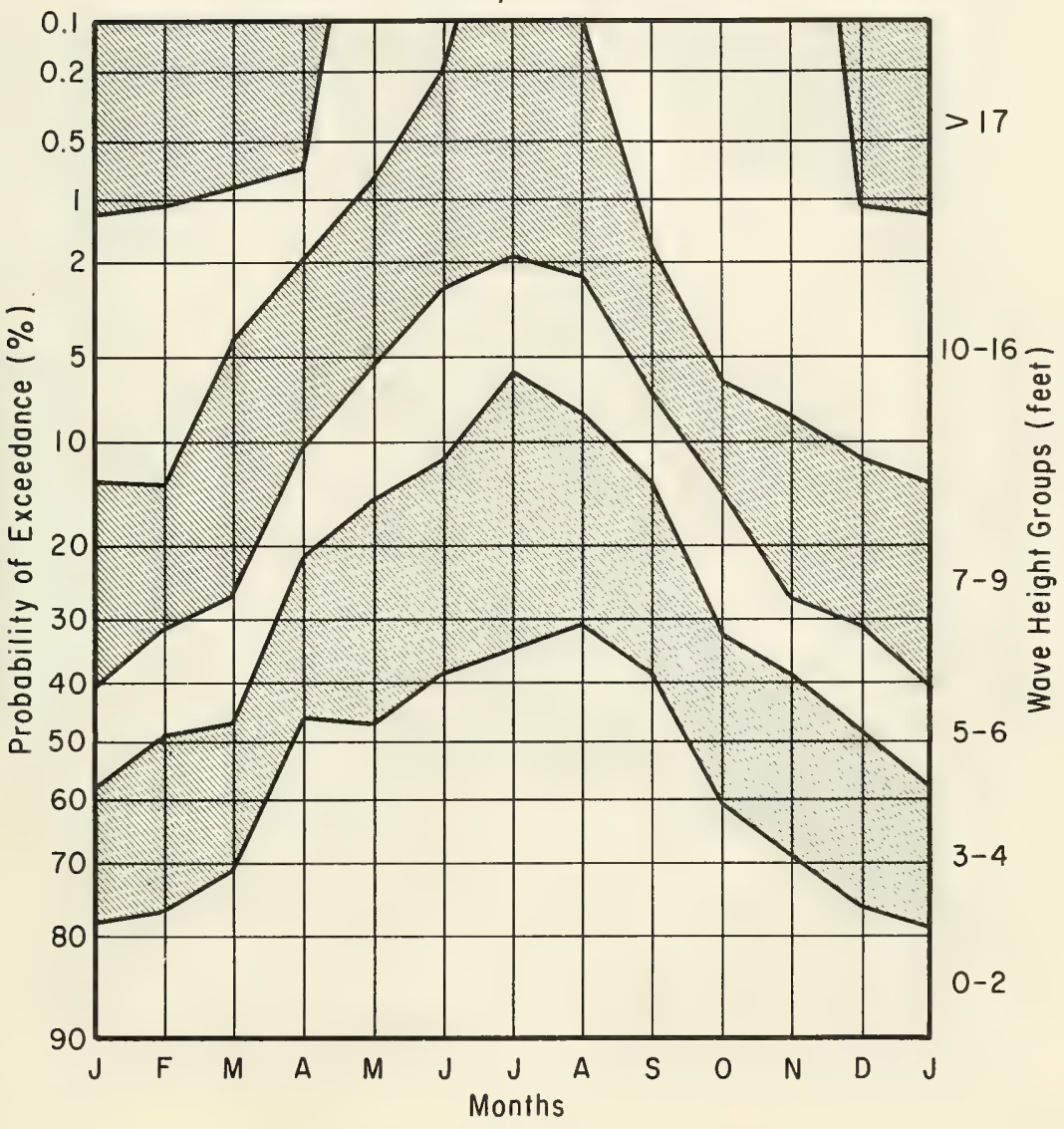

Figure 10. Monthly percent exceedance of wave height Boston, Massachusetts. 
Noval Weather Service

Summary of Synoptic Meterological Observations

$1963-1968$

$\left(38^{\circ}\right.$ to $40^{\circ} \mathrm{N}, 72^{\circ} \mathrm{W}$ to Coast)

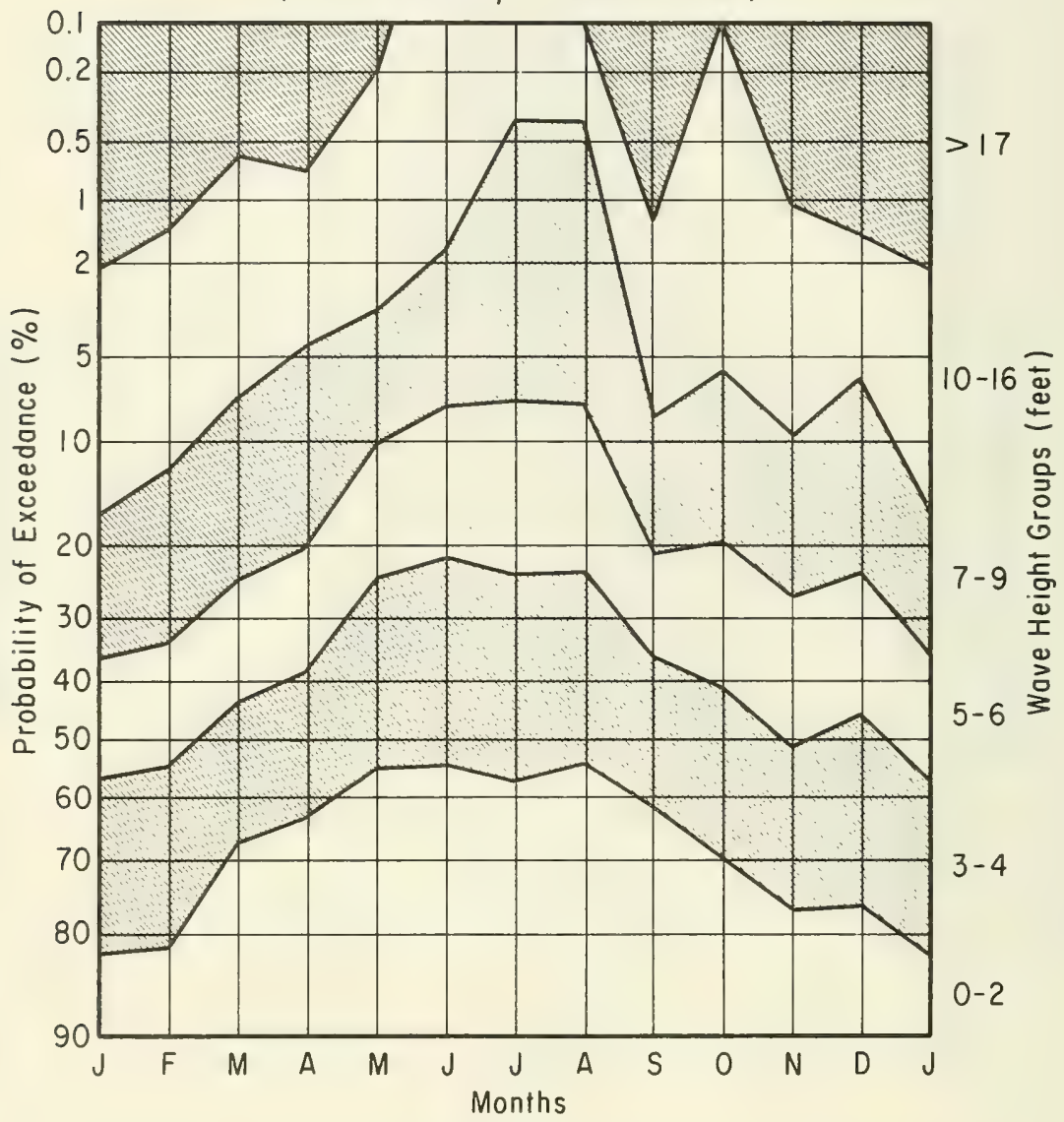

Figure 11. Monthly percent exceedance of wave height Atlantic City, New Jersey. 
Naval Weather Service

Summary of Synoptic Meterological Observations

1963-1968

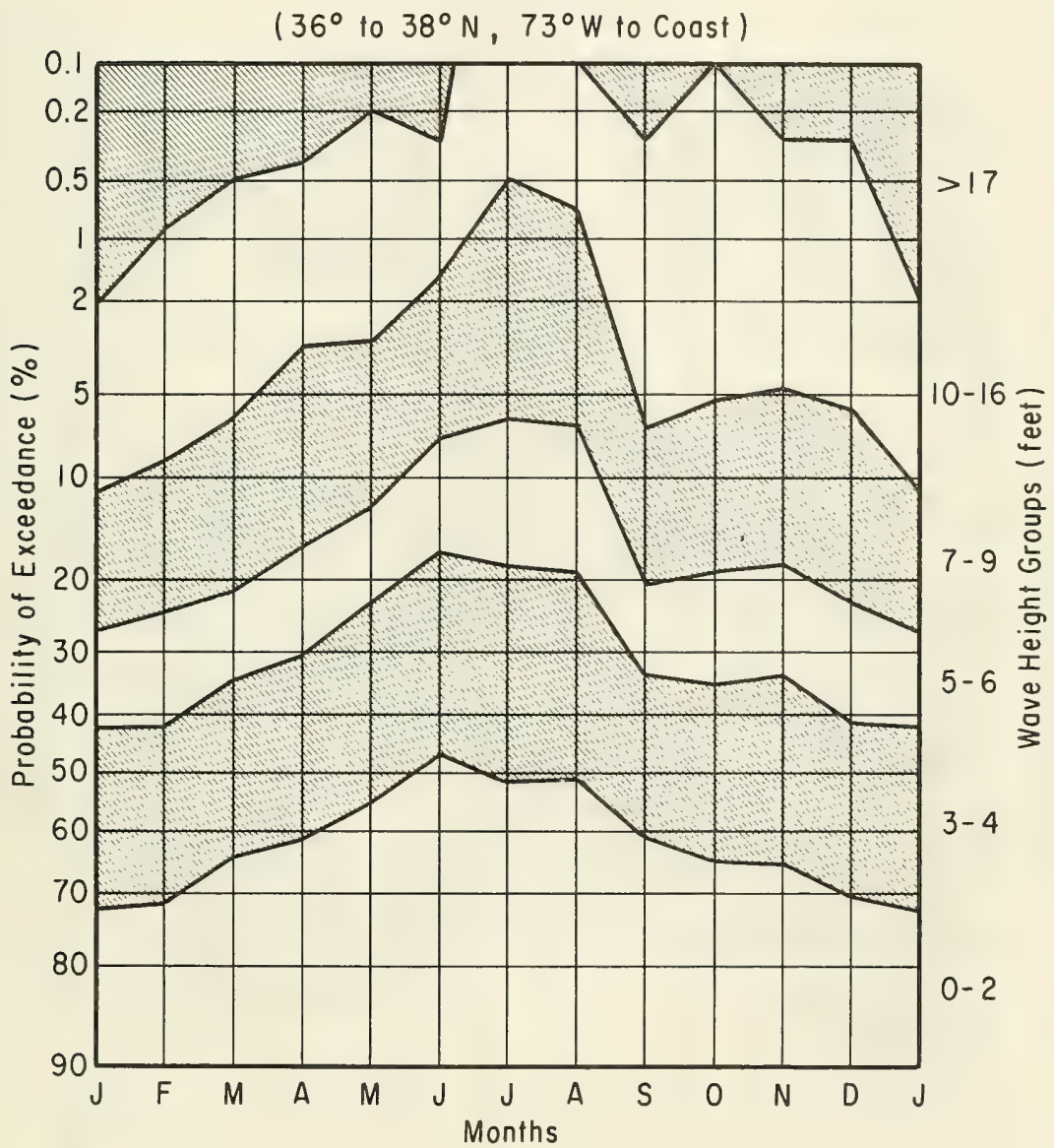

Figure 12. Monthly percent exceedance of wave height Norfolk, Virginia. 
Noval Weother Service

Summary of Synoptic Meterological Observations

$1963-1968$

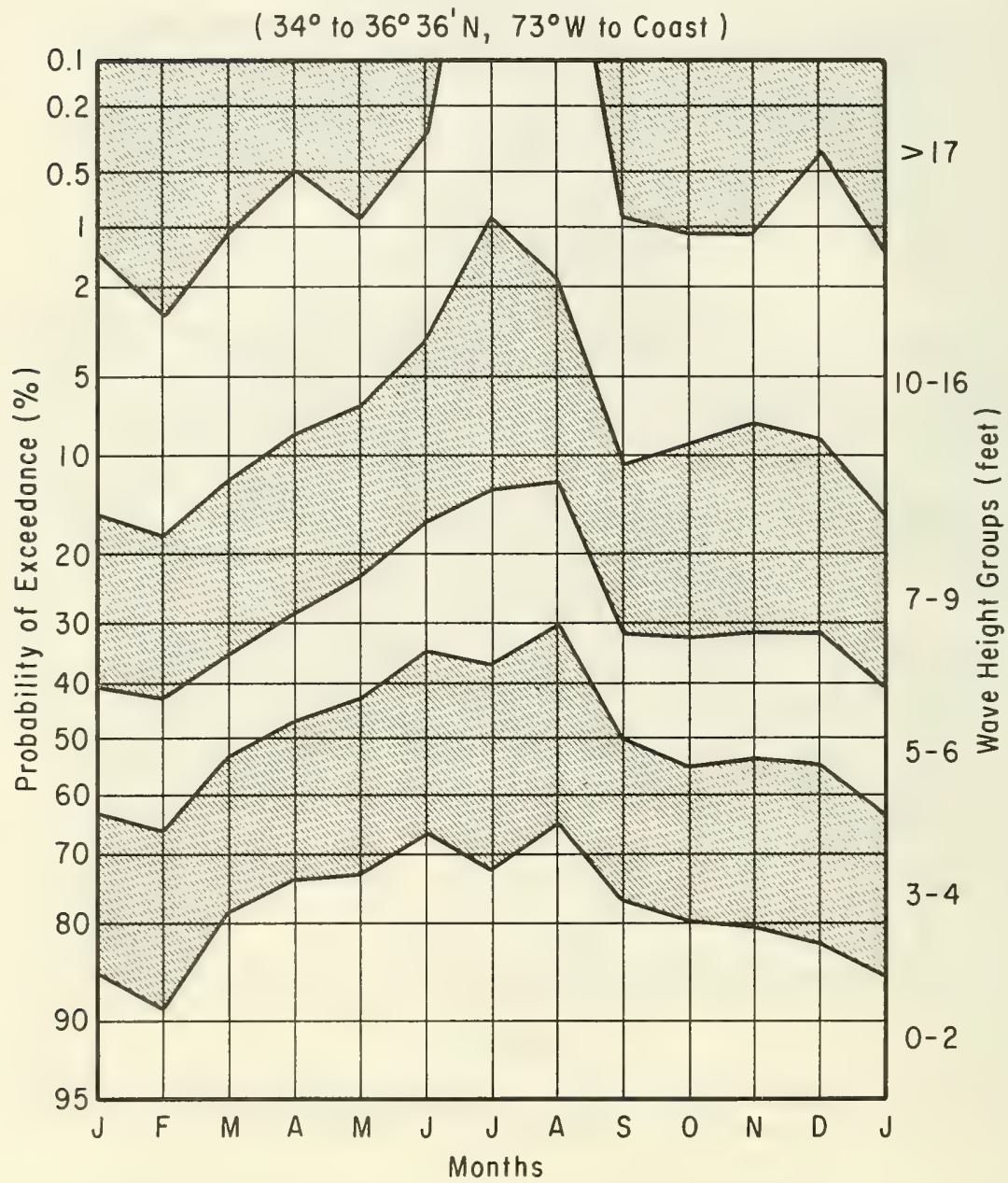

Figure 13. Monthly percent exceedance of wave height Cape Hatteras, North Carolina. 


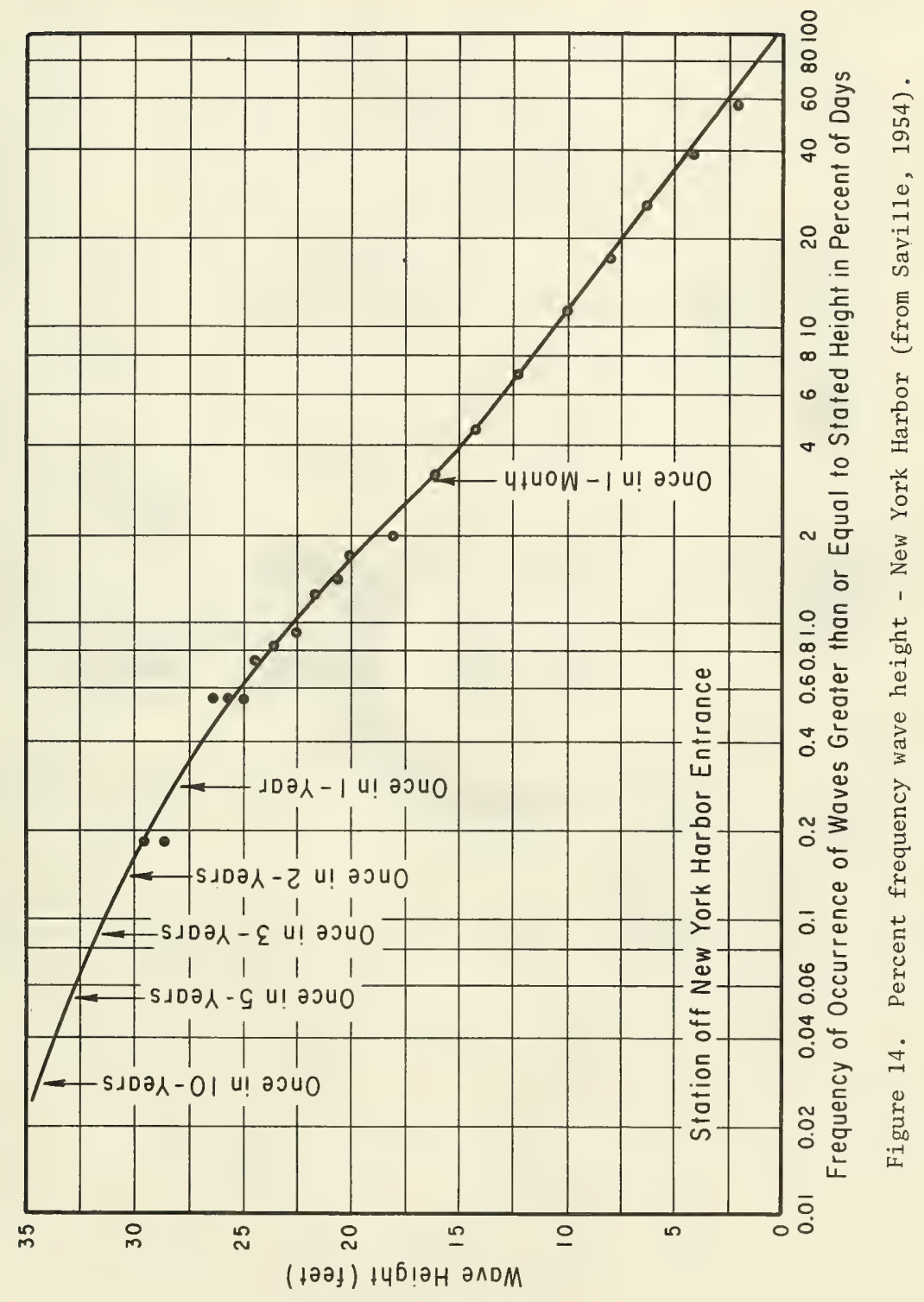




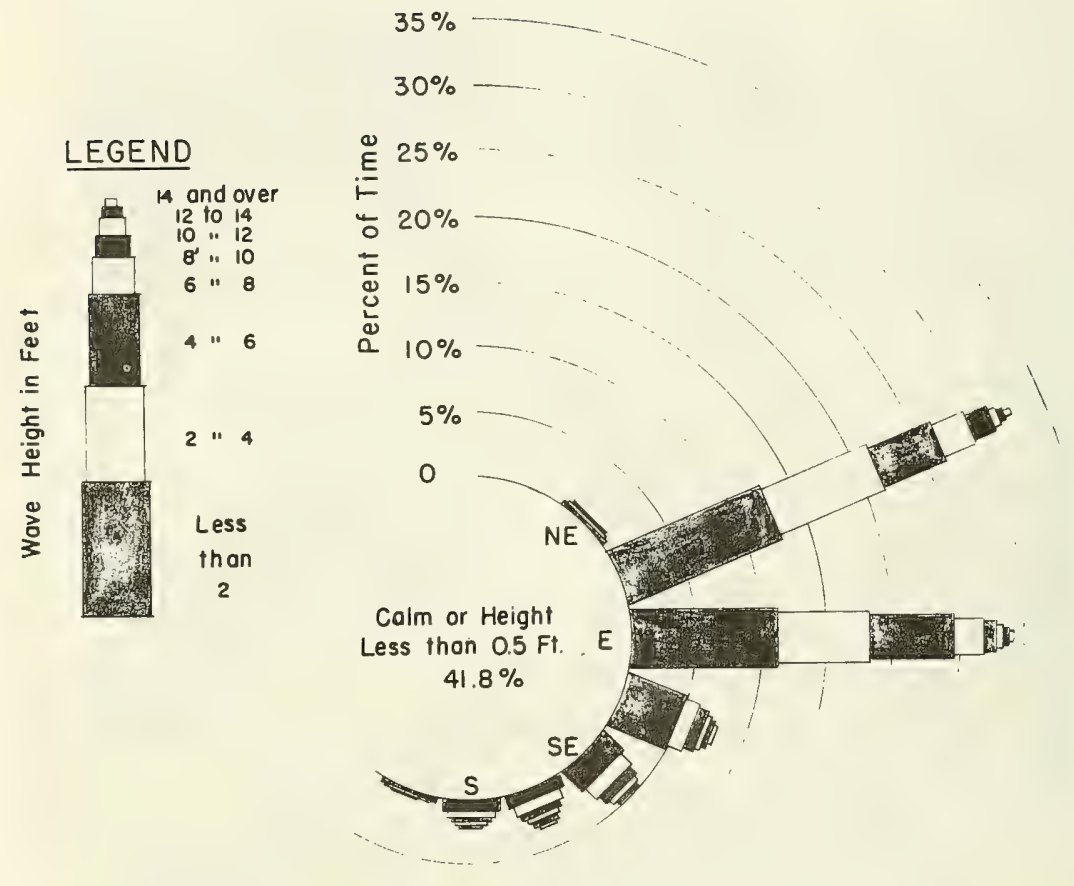

Station off New York Harbor Entrance

Figure 15. Wave rose (from Saville, 1954). 
(b) Construction in the basin, of bottom slabs and caisson walls high enough to permit flotation.

(c) Establishment of an outfitting site for completing units before tow to final breakwater site. site.

(d) Flooding of basin and towing of units to outfitting

(e) Completion of upper parts of units, ballasting, and outfitting with handling gear.

(f) Necessary bottom preparation at breakwater site. site.

(g) Towing, locating, and sinking units at breakwater

(h) Completion of ballasting, interlocking keys, and other onsite construction.

Individual operations making up the program are discussed in the following paragraphs. The complete operation is described in Section III, 3; further description is included under Section IV which forms the basis for the cost estimate. A general pictorial view of the onshore construction areas is shown in Figure 5.

\section{Detailed Operations.}

a. Fabrication of Concrete Breakwater Units. The most economical way to fabricate the precast concrete breakwater units is to first cast a lower section with sufficient height to provide flotation, then tow this section to a protected outfitting site in deeper water and construct the remainder of the unit while floating. Casting the lower section can be done in one of two ways. One way is to cast the lower section in a drydock; however, few drydocks are capable of accommodating more than two units at one time and the cost of a drydock specifically built for this operation would be prohibitive. Another way is to excavate a large basin in a protected cove along the shore to the required depth (as deep as possible as governed by existing access channels). On the seaward side, the basin would be enclosed by a dike as shown in Figure 16. Such a basin would provide an area in which six units could be cast at one time to a height of 50 feet. The minimum draft of each partially completed unit would be about 25 feet. After the six units are built to this leve1, the basin would be flooded to float the units, and an opening cut through the enclosing dike. At high tide the units would be towed out, one at a time, and brought to an outfitting site where the units can be completed. The dike opening is again closed, the water within the basin pumped out, and construction started on six more units.

Careful monitoring of adjacent shores during casting operations must be maintained to determine the effect of such construction on the 


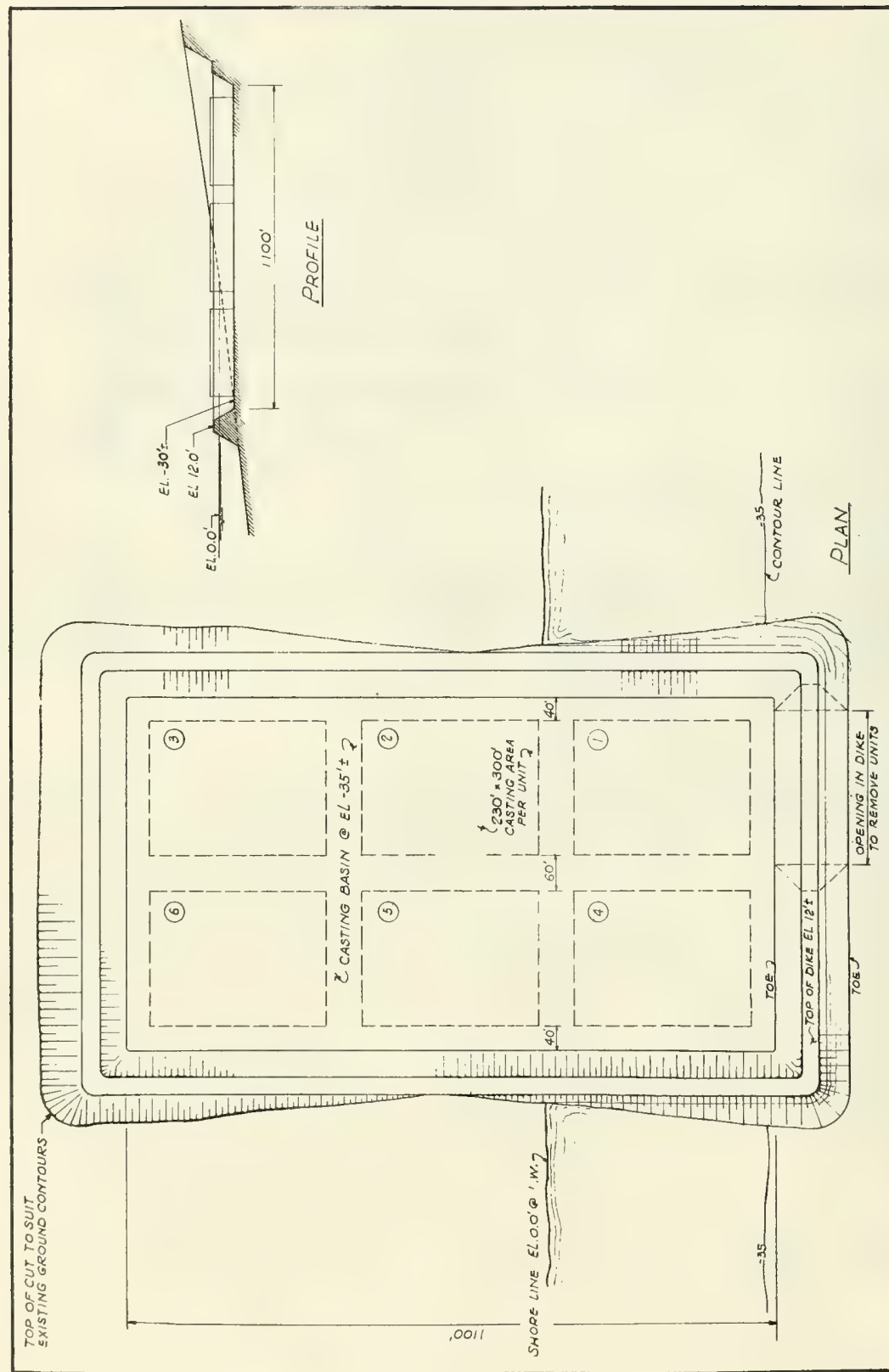


littoral drift in the area, and on the buildup or erosion of nearby beach areas.

Other facilities are necessary, in conjunction with, and adjacent to the casting basin, i.e., a carpenters shop and the area where forms for casting units are prepared and serviced; an area where reinforcing steel is stored and preassembled into cages for placing in the forms; a concrete batch plant with adjoining storage area for cement, sand and stone aggregate; and other miscellaneous facilities.

The choice of a site for completing caisson construction after it has been towed out of the casting basin must meet several requirements. Since the units are afloat, waves at the site must be low, with low current velocities, and the units must be protected from extreme winds.

Water deep enough to accommodate the maximum $d_{i}$ aft of completed units is required at the outfitting site and along the towing route to the breakwater site. During caisson construction at the outfitting site, drafts and freeboards will change with construction stages. Concrete placement must be scheduled to maintain the unit on an even kee1, longitudinally and transversely, at all times.

The outfitting site should be as close as possible to the breakwater site to reduce the time required for towing and setting operations, thus reducing weather hazards.

b. Bottom Screeding Procedure. Placing the grave1 or crushed stone bed and leveling or screeding to proper elevation before setting caisson units will be performed from previously set units. Working from inplace units eliminates the necessity of working from floating equipment with the attendant difficulties and downtime due to rough seas.

The screeding rig would consist of a gantry, supported at the back end on previously set units and at the forward end by pipe legs and floats. The main truss, which would be free to run from a position above the set units out over the entire area on which the next unit was to be set, would be hung from the gantry. The main truss supports a travelercarrying stone hopper from which telescopic gravel pipes are suspended to feed the screed box at the bottom. The stone is laid and leveled from the screed box. General arrangements of the screeding rig are shown in Figures 17, 18, and 19.

To set the first permanent unit, the rig would first be erected on two units temporarily set on the natural bottom without preliminary bottom preparation. The selection of such a suitable area adjacent to the main breakwater site, is an important requirement in planning the site location.

With the gantry run fully forward, the rig would extend from the previously set units over the 246-foot length of the next unit to be placed, and be supported on the legs and floats beyond. The system of legs and floats provides a buoyant force at the forward end of the gantry 


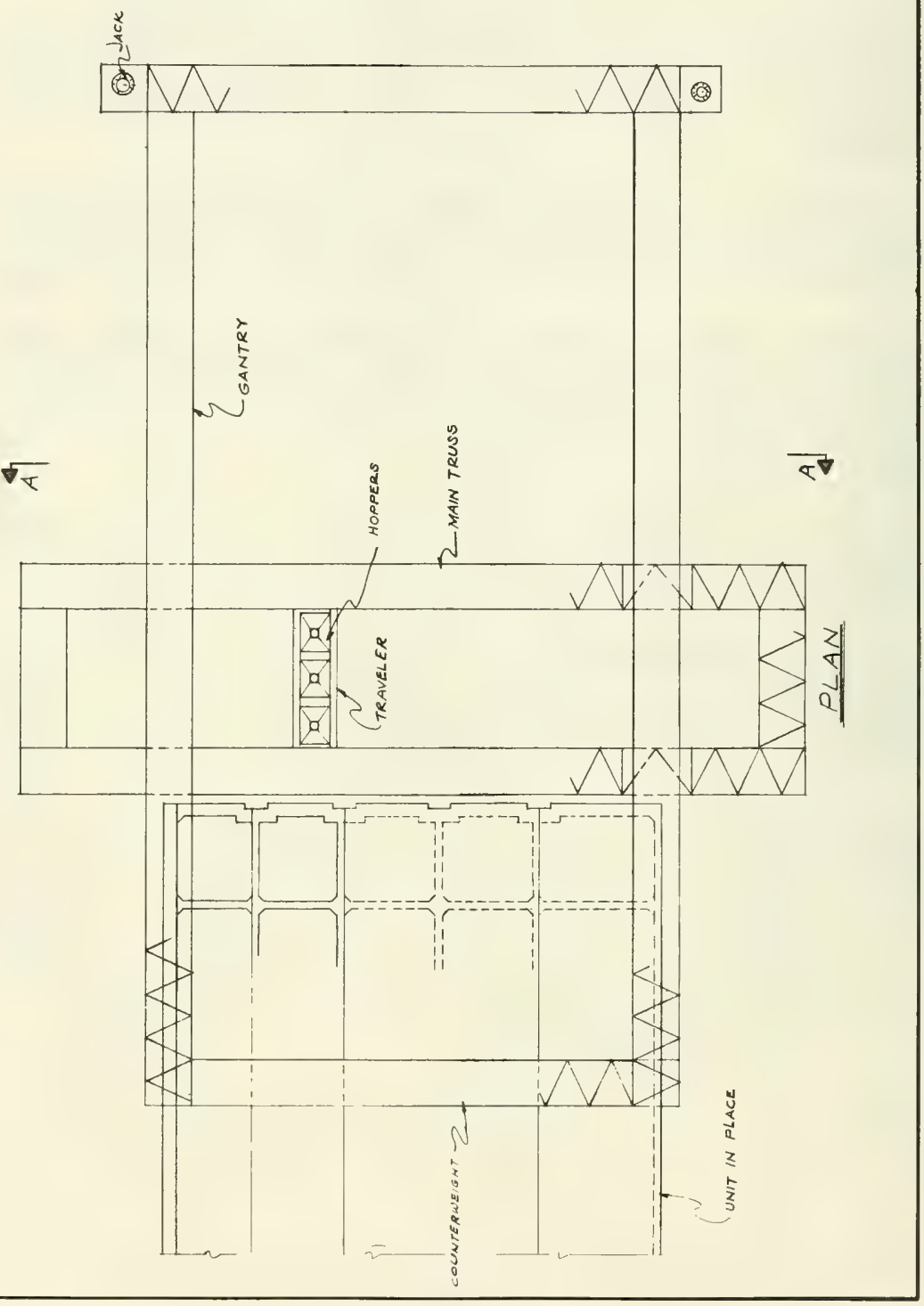

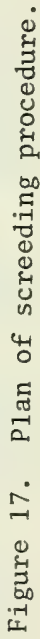




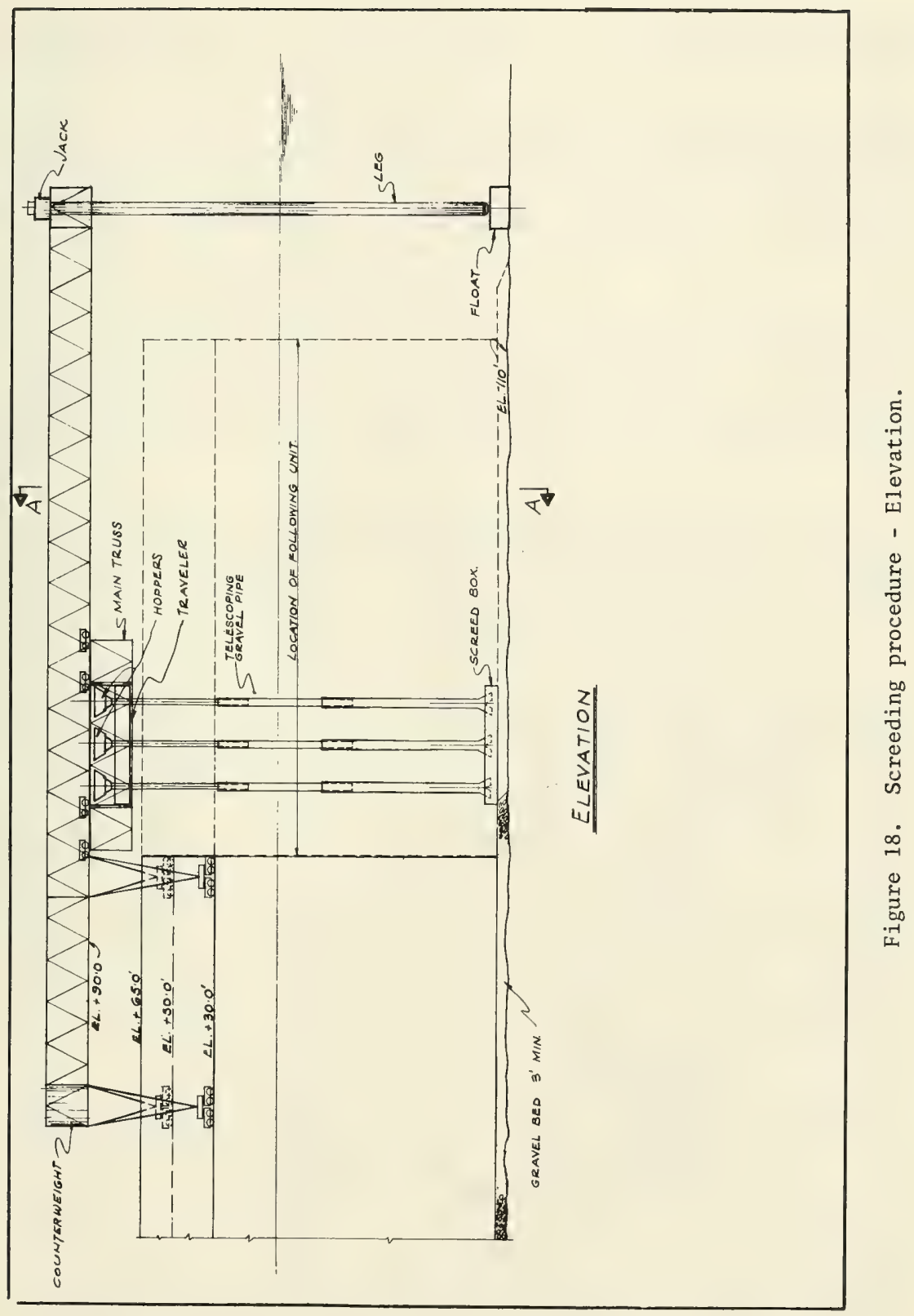




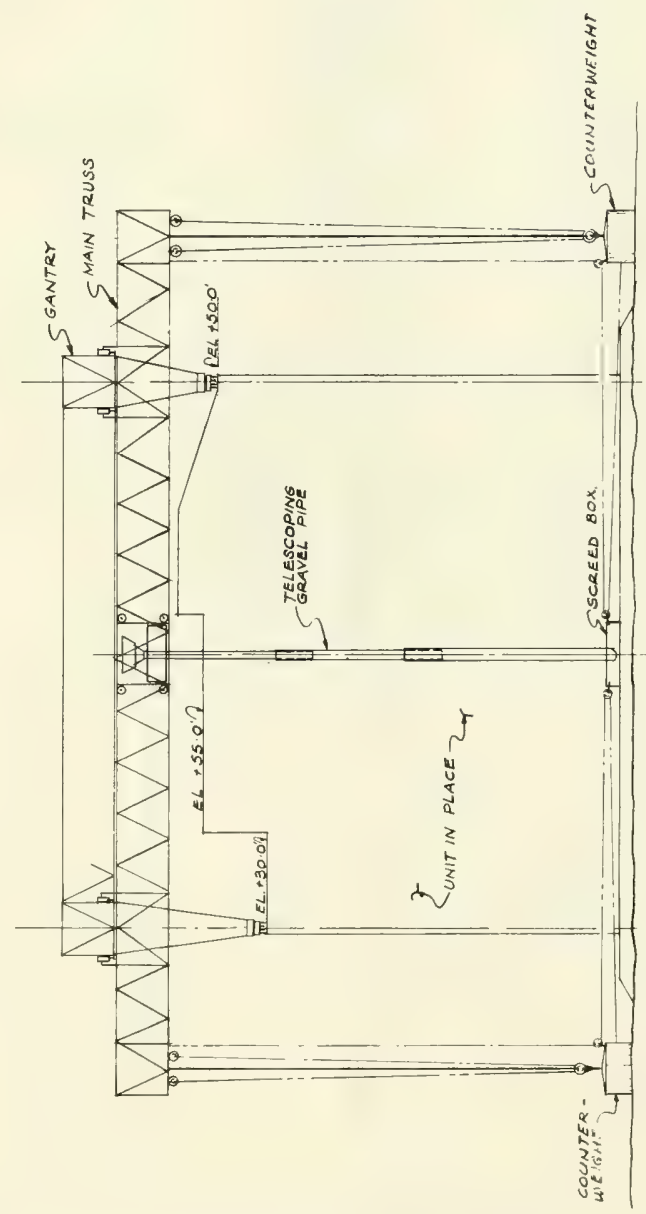

\begin{tabular}{l|}
+ \\
+ \\
7 \\
0 \\
5 \\
4 \\
4 \\
$\omega$
\end{tabular}

हే 
to carry part of the load. The balance of the load is distributed over the sea bottom by the floats.

The main truss would be required to operate from five different positions along the longitudinal axis of the breakwater during placement of each unit. The screed box, while depositing and leveling stone, and traveling across the structure axis, would be positioned and moved with the aid of counterweights resting on the bottom beneath the extreme ends of the main truss. The counterweights would be suspended from the main truss and relocated for each position.

Once the bed is prepared for the next unit, the screed box would be run to one end of the main truss; then, the screed box and the counterweights would be raised free of the bottom, and the main truss fully retracted on the gantry to a position adjacent to the set unit. At this point, the screed box and counterweights are hanging far enough out from the side to clear the inplace units supporting the gantry.

With the main truss in a fully retracted position, the pipe legs and floats are jacked free of the bottom with the buoyant force of the floats still partly supporting the unloaded gantry. At this stage the entire assembly can be run back on its track onto the next-to-last previously set unit, leaving the newly screeded area free of obstructions for setting the next unit.

With the new unit in place and secured, gantry track wil1 be laid, and the gantry moved ahead for laying and screeding the bed for the next unit. This will not interfere with filling of the unit with sand and stone, which should be a continuous operation once the unit is on the bottom.

Once the gantry is operating from permanently set units, the first two temporary units can be refloated and placed in their final position.

c. Alternate Screeding Procedure. In an alternate screeding procedure, the operation may be carried on from specially rigged barges, from which the stone is placed and leveled, as shown in Figure 20. Because of the need for good weather conditions, the use of floating equipment should be avoided. However, it may be necessary under certain conditions, e.g., bottom preparation for the first units placed.

After each precast unit has been placed, preparations are made for screeding the bed of the next unit. Where necessary for placing additional units, screed barge anchors are picked up and relocated. The screed barge is moved into position and anchor lines connected to anchorline buoys. The anchor lines are tensioned and the screed barge is positioned for the screeding operation. A screed-pulling anchor is then planted; wire ropes for the counterweights are laid out and the counterweights set on the bottom. Ballast tanks in the barge are flooded and the hull submerged to the proper depth below water level by tensioning the counterweight wire ropes. In a semisubmerged position, the barge 


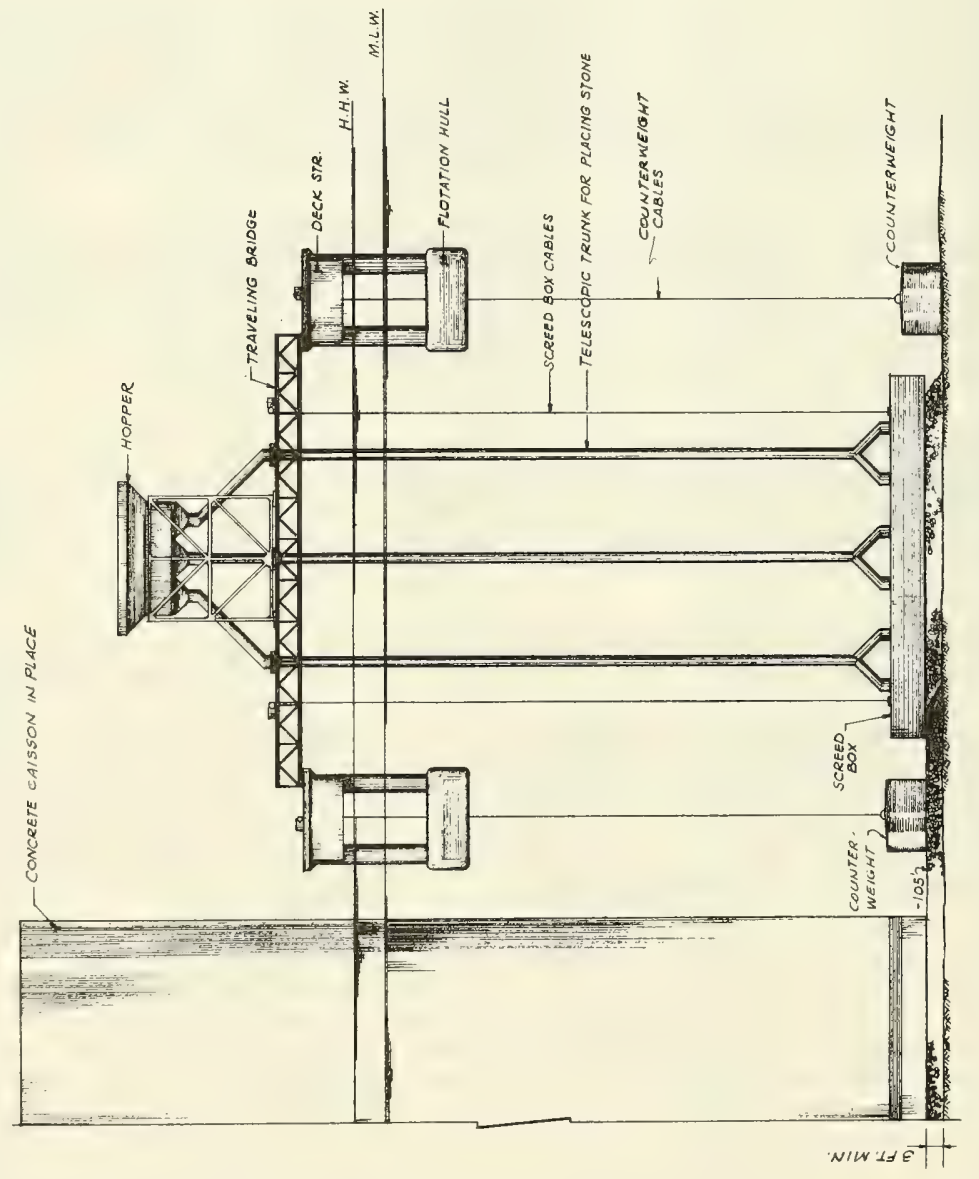


can be held at a constant elevation above the bottom, with a minimum of wave-induced motion.

A screed box is hung by cables from a traveling bridge mounted on the deck of the screed barge. These cables are adjustable so that the underside of the box can be lowered to a predetermined elevation. Once the screed is lowered to the desired elevation below the barge deck, screeding is ready to proceed.

A stone-placing barge, with crane on deck, is then brought alongside the screed barge. An aggregate-supply barge is positioned and tied outboard of the crane barge. Aggregate is placed in the hopper mounted on the traveling bridge and fed into the screed box through telescopic trunk pipes which hang from the traveling bridge. As the screed box is pulled forward, the crushed stone bedding is deposited in a layer on the bottom. The top of the layer is struck off evenly by the bottom edge of the trailing side of the screed box. The screed box is slowly pulled forward until the run is completed.

The screed box is then partially raised, and the screed barge refloated; the counterweights are raised slightly and the screed barge moved laterally to the next position. When the barge is in position, the counterweights are reset, the barge hull submerged and the screed box lowered. The barge is then ready for the next screeding run. When sufficient stone bed has been placed and screeded, the screed barge casts off its anchor lines and is removed from the site so that the next concrete breakwater unit can be brought in and set. The cycle is repeated as necessary.

d. Setting Concrete Breakwater Units. Each precast unit is towed from the outfitting area by two tugs. As the unit approaches the breakwater site, the tugs move to each side of the unit and slowly pull it close to the setting location. Hauling lines are secured between the floating unit and the leading end of the previously set inplace unit. Winches mounted on the inplace unit slowly draw the floating unit into position and then is partially flooded. The tugs hold the floating unit in line against wind, waves and current. This sequence of operations is illustrated in Figure 21.

The unit, when pulled closer to a final setting position, has been flooded enough so that the bottom is within inches of the screeded stone bed. A final check is made on alinement of the floating unit and, by adding additional ballast, is founded on the stone bed. Fu11 ballast is then added for stability.

Settlement of the units should be less than 2 inches because of the designed low bottom pressure.

The winches are removed from the preceding unit and reset on the newly founded unit. A11 towing bitts, cleats and towing lines are removed and returned to the finishing site to be mounted on another breakwater unit. 


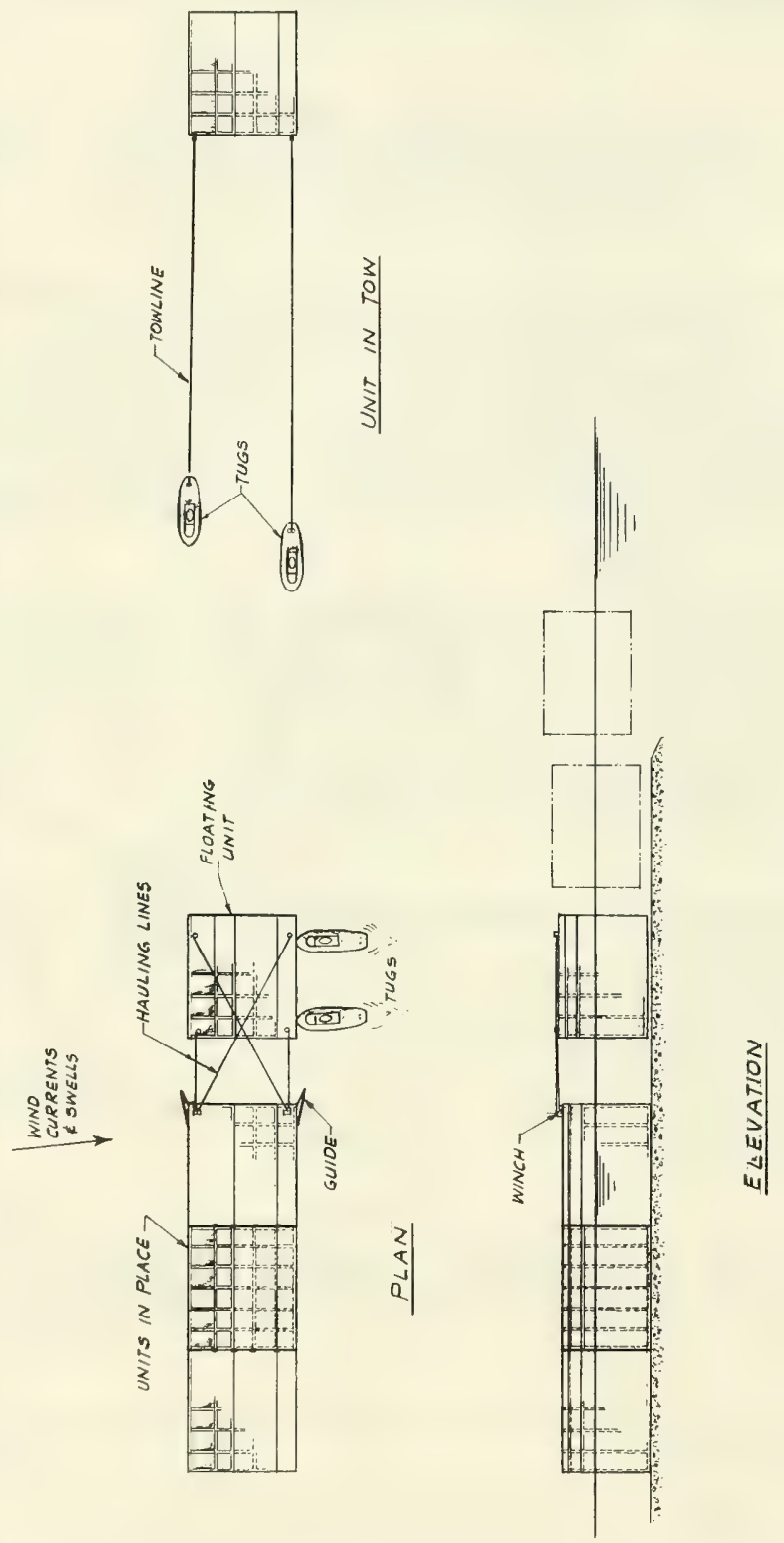

Oే

 
In spite of the advanced construction techniques discussed, the inherent problems in deepwater seaport construction will lead to new construction methods and techniques. However, the development of new techniques is most likely during the actual construction when experimentation can be performed.

At this stage of the planning, known methods, adapted and modified to the particular needs of this project, are best considered. Planning based on established techniques however, should tend to keep any construction schedule and cost estimate on the conservative side.

A construction schedule, including implementation studies, preliminary and final engineering, land acquisition, construction contracts and the final construction, is presented in Table 1.

\section{CONSTRUCTION COSTS}

1. Comments and Assumptions.

The construction cost of a structure such as the proposed offshore breakwater-oil storage system depends on many variables, and includes the following:

(a) Breakwater site. Geographical location and sea, weather and bottom conditions at the site.

(b) Precasting and outfitting sites. Cost of building facilities versus possibility of adapting established sites to needs; location relative to each other and to breakwater site.

(c) Design criteria. Particularly for material specifications.

(d) Cost of materials and 1abor. Comparative costs ai various possible locations of all sites.

(e) Construction methods.

To prepare a basic estimate, certain assumptions were made. Once a basic estimate was completed, alternates were worked out to include variations required for the specific conditions under consideration.

Assumptions for the basic estimate according to the above-1isted variables are:

a. Breakwater Site. The proposed breakwater site was assumed to be off Long Branch, New Jersey, at a distance required to provide the indicated water depth without dredging. The exact location would be chosen 
Table 1. Construction Schedule

\begin{tabular}{|c|c|c|c|c|c|c|c|c|}
\hline \multirow{2}{*}{ Item } & \multicolumn{8}{|c|}{ Years } \\
\hline & 1 & 2 & 3 & 4 & 5 & 6 & 7 & 8 \\
\hline \multicolumn{9}{|l|}{ Implementation Studies } \\
\hline \multicolumn{9}{|l|}{ Financing } \\
\hline \multicolumn{9}{|l|}{ Legal } \\
\hline \multicolumn{9}{|l|}{ Administrative } \\
\hline \multicolumn{9}{|l|}{ Preliminary Engineering } \\
\hline \multicolumn{9}{|c|}{ Engineering } \\
\hline \multicolumn{9}{|c|}{$\begin{array}{l}\text { Field surveys, borings, } \\
\text { Oceanography, meteorology, etc. }\end{array}$} \\
\hline \multicolumn{9}{|c|}{ Model tests } \\
\hline \multicolumn{9}{|l|}{ Environmental impact study } \\
\hline \multicolumn{9}{|l|}{ Final Engineering } \\
\hline \multicolumn{9}{|l|}{ Final design } \\
\hline \multicolumn{9}{|l|}{$\begin{array}{l}\text { Contract documents } \\
\text { (Incl. specs.) }\end{array}$} \\
\hline \multicolumn{9}{|l|}{ Land Acquisition } \\
\hline \multicolumn{9}{|l|}{ Construction Contracts } \\
\hline \multicolumn{9}{|l|}{ Advertise for bids } \\
\hline \multicolumn{9}{|l|}{ Analyze bids } \\
\hline \multicolumn{9}{|l|}{ Award contracts } \\
\hline \multicolumn{9}{|l|}{ Construction } \\
\hline \multicolumn{9}{|l|}{ Prepare precasting site } \\
\hline \multicolumn{9}{|l|}{ Pouring of lower sections } \\
\hline \multicolumn{9}{|l|}{ Prepare outfitting pier } \\
\hline \multicolumn{9}{|l|}{$\begin{array}{l}\text { Pour upper sections } \\
\text { and outfit }\end{array}$} \\
\hline \multicolumn{9}{|l|}{ Prepare breakwater site } \\
\hline \multicolumn{9}{|l|}{ Towing and placing units } \\
\hline Completion of site work & & & & & & & & \\
\hline
\end{tabular}


to avoid the need for bottom preparation before depositing the bottom rock material. If small differences is elevation along the breakwater axis were unavoidable, the casting height of the units could be varied accordingly.

The cost estimate, with recommended modifications to adjust for local costs, is believed valid for a breakwater located at any point along the northern U.S. east coast as far south as Cape Hatteras.

b. Precasting and Outfitting Sites. The basic approach for construction of the units is to cast, in a dry basin, the base slab and enough of the walls to permit safe flotation, and to complete casting and outfitting alongside a pier while afloat. Therefore, the outfitting site must have adequate depth to float the completed empty units (with the possible addition of some stabilizing ballast). The maximum net draft of the largest units is estimated to be 63 feet; hence a 70 -foot depth was assumed necessary, including allowance for tide variations and minor ballasting.

Since the outfitting site will be relatively unprotected, the cost estimate includes three additional units 50 feet in height to be used as temporary protection at this stage of the operation (money should be available for outfitting site protection, though possibly using a different technique).

These conditions severely limit possible outfitting locations along the east coast. After considerable study, the north shore of eastern Long Island, fronted by Long Island Sound, located in the vicinity of Port Jefferson, New York, was selected as a suitable site. In this area, 70-foot depths occur about one-half mile offshore. To reduce the towing distance from the dry basin to the outfitting pier, and to keep operations close together for supervision during construction, the dry basin site was assumed to be within 5 to 10 miles of the outfitting pier.

The largest units are designed for 90 - to 110-foot depths, and any breakwater site south of Cape Cod would require precasting in Long Island Sound. Suitable precasting sites north of Cape Cod could be found near Portland, Maine. However, for a shallower site near the Delaware or Chesapeake Bays, local precasting sites can probably be found.

Ocean tow of a completed unit to the breakwater site is estimated to require four 1,200 to 1,500 horsepower, oceangoing tugs for reasonable speed and adequate safety. The tows must be scheduled for suitable weather. The period during positioning and final sinking of the units will also require relatively calm weather with tugs standing by at the site.

Estimated towing costs were based on a tow from Port Jefferson to Long Branch via Montauk Point. Towing costs for other sites can be obtained by assuming towing rates of approximately $\$ 150$ per nautical mile. 
c. Design Criteria. Material and workmanship standards have been assumed as first class to provide the best durability at such an exposed offshore location. Assumed standards include that: (a) concrete was to have a compressive strength of 3,500 pounds per square inch; (b) rock products were as dense and durable as available; (c) holes cast in perforated walls were to have rounded edges at faces formed by using either a precast concrete liner or reusable steel forms; (d) a 0.125-inch steel sheet liner was required in oil storage compartments to protect against leakage through concrete cracks (with the low operating head expected, but further study may indicate that plastic liners are adequate and more economica1); (e) a 2-foot layer of quarry-run rock over the sand in filled compartments was used to protect against splash and minor wave action within cells; (f) grout for preplaced aggregate contained a minimum of cement since it is primarily for mass and stiffness rather than for strength or durability.

A paved roadway was assumed along the low level deck along the inner side of the breakwater for servicing various mechanical and electrical installations on the oil storage breakwater. The paved roadway was not deemed necessary for the nonstorage type. Mechanical and electrical installations, including aids to navigation, fenders, mooring hardware, and berth dredging, have not been included in the cost estimate.

d. Cost of Materials and Labor. For all labor performed in areas north of Cape Cod, labor costs would be about 15 percent less than the basic estimate, reflecting lower wage rates and better efficiency. Labor costs in the Delaware Bay area would be about 10 percent lower, and about 15 percent lower in the Chesapeake Bay area. The basic estimate can be adjusted accordingly to reflect the lower wage scales in these areas.

Towing costs per mile per unit remain the same throughout these areas.

Material cost variations at different sites would nearly balance out. This is because the various rock products make up the largest material requirements, and in cheaper labor areas rock sources are usually distant from the point of use, and vice versa. Hence, lower quarrying costs are offset by higher delivery costs.

e. Construction Methods. The plan for an initial precasting basin requires an open excavation to about -30 foot elevation along the edge of Long Island Sound at Port Jefferson. The excavated spoil would be used to build up berms around the pit for working areas and to build a closure dike across the side fronting on the Sound.

The planned size is 1,100 feet by 800 feet of working area at the bottom of the sloping sides to accommodate six of the largest units, with adequate roadways and working space around each unit. A concrete slab is to be provided for each unit as a working surface over which a parting compound or fabric is placed so the units float free when the basin is 
flooded. Riprap protection for the dike is to be provided and the basin equipped with wellpoints or deep wells to dewater the sandy soil in the area.

After the first six units are cast to a minimum height of about 50 feet, the basin is flooded at a controlled rate and enough of the dike removed to provide an opening wide enough for each unit to be floated out one at a time. The dike is then rebuilt, the basin dewatered and the next cycle of six units constructed. Since concrete placing is expected to be easiest at this location, as much casting as possible is planned under the restriction imposed by available channel depths to the outfitting pier.

Because of the large concrete volumes and the need for a continuous supply (about 1,600 cubic yards per day at both the precasting site and outfitting site), a separate concrete plant was planned for each site with distribution by trucks and buckets, perhaps requiring multiple shifts.

Since adequate water depths occur some distance from shore at the outfitting pier site, and probably in an area without much natural protection, an access trest1e, 2,000 feet long and 30 feet wide for two-1ane access with a 600 - by 40-foot working area at the offshore end is planned. The cost of this facility has been written off against the project, but circumstances may suggest a permanent structure for recreation or other use.

Because of the size of the units (215 by 246 feet), the material handling reach requires equipping each unit with a tower crane during construction.

Since the boxes are designed with an neally uniform cross section, slip forms appear to provide the quickest and most economical method of construction. Generally, units under construction will not float leve1, and surveying control will require special procedures. Such procedures have been implemented on similar work.

A template rig may be used to serve as a temporary working platform for positioning and alining the first unit at the final site. Once the first unit is set, screeding equipment erected and construction started, the extra platform is no longer needed.

As estimated, positioning the first unit will take longer than subsequent units. The precise location is not critical but alinement must be close to final design alinement so that the planned protection is obtained. The first unit serves as a point of reference when in place so that following units can be positioned more easily and rapidly.

Although the materials within the boxes seem secondary, the quantities are large enough to justify consideration. The boxes would be sunk with 
water ballast, but the heavier aggregate materials must be added promptly to obtain further stability. It is assumed that sandfill can be obtained locally without charge by use of a hopper dredge and pumped directly into place without negligible adverse environmental or ecological effects. Rockfill or preplaced aggregate should arrive at the job in self-unloading vessels. Quantities required are large enough to justify bringing in such equipment if not locally available. Riprap toe protection would be placed from barges with a floating derrick, and, since exact placement in such depths is not practical, the cost estimate allows for some overrun.

f. Miscellaneous. The estimate represents construction contract prices only, excluding costs of design, inspection, borings, and model tests.

Costs used throughout the estimate are based on market prices for December 1972. Inflation escalation is suggested at a rate of 5 percent per year to any proposed construction contract date.

Costs are separated into installation costs and material costs. Material costs are the delivered-on-site cost of all materials, permanent and temporary. A11 other costs, including such nonlabor items as construction equipment charges, towing, and insurance, are installation costs. Labor costs in the estimate include direct payroll and fringe items as benefits, payroll tax, and workman's compensation insurance.

For making regional adjustments, 1 abor costs amount to slightly over one-half of the total installation cost. Breakwater-site labor is about one-fifth of the total installation cost.

The total construction schedule may extend over several years, and scheduling construction to avoid as much winter work as possible is advisable. Placing the first unit at the site in the best weather possible is absolutely imperative, since this will be a difficult and exacting operation under the best conditions.

\section{Cost Estimates and Cost Curves.}

a. Basic Estimate. Basic estimate of construction costs for the breakwater structure shown in Figure 1 (8,600 linear feet - 36 units) at a site off Long Branch, New Jersey, in accordance with descriptions and general assumptions discussed previously, is given in Table 2 .

Table 2. Estimated Basic Cost

\begin{tabular}{c|c|c|c|c}
\hline \multirow{2}{*}{$\begin{array}{c}\text { Water } \\
\text { Depth } \\
\text { (feet) }\end{array}$} & \multicolumn{2}{|c|}{$\begin{array}{c}\text { Cost With Oil Storage } \\
\text { Capacity }\end{array}$} & \multicolumn{2}{c}{$\begin{array}{c}\text { Cost Without Oil Storage } \\
\text { Capacity }\end{array}$} \\
\cline { 2 - 5 } & Tota1 & Per Linear Foot & Total & Per Linear Foot \\
\hline \hline 110 & $\$ 653,774,000$ & $\$ 76,000$ & $\$ 503,557,000$ & $\$ 58,600$ \\
90 & $540,935,000$ & 62,900 & $411,524,000$ & 47,900 \\
70 & $441,635,000$ & 51,400 & $340,073,000$ & 39,500 \\
50 & $281,565,000$ & 32,700 & $197,853,000$ & 23,000 \\
\hline \hline
\end{tabular}


b. Modified Estimates for Varied Locations. The basic estimate can be modified (discussed earlier) by applying percentage variations to the various labor costs and a mileage factor for towing costs to the alternate location and arrive at an estimate of construction costs at any location along the northeast coast. Examples of modified estimates for two locations are shown in Table 3 .

Table 3. Modified Estimated Cost for Two Atlantic Coast Locations

\begin{tabular}{|c|c|c|}
\hline Method of Computation & Total Cost & $\begin{array}{c}\text { Cost } \\
\text { Per Linear Foot } \\
\end{array}$ \\
\hline $\begin{array}{l}\text { With storage, } 110^{\prime} \text { water depth; } \\
\text { basic cost \& Long Branch }\end{array}$ & $\$ 653,774,000$ & $\$ 76,000$ \\
\hline $\begin{array}{l}\text { Tow mileage }-240 \text { miles less } \\
\$ 150 / \mathrm{mi}=\$ 36,000 / \text { unit }=\end{array}$ & $-1,296,000$ & -150 \\
\hline $\begin{array}{l}\text { Labor }-15 \% \text { reduction in onshore } \\
\text { labor } 44 \% \times \$ 395,871,000=\end{array}$ & $-26,127,000$ & $-3,040$ \\
\hline $\begin{array}{l}\text { Labor - } 15 \% \text { reduction in onsite } \\
\text { labor } 11 \% \text { X } \$ 395,871,000=\end{array}$ & $-6,532,000$ & -760 \\
\hline Totals & $\$ 619,819,000$ & $\$ 72,050$ \\
\hline $\begin{array}{c}\text { Cost With Oil Storage } \\
\text { Capacity }\end{array}$ & \multicolumn{2}{|c|}{$\begin{array}{r}\text { Cost Without Oil Storage } \\
\text { Capacity }\end{array}$} \\
\hline Per Linear Foot & Total & Per Linear Foot \\
\hline
\end{tabular}

Estimated Cost - Boston

\begin{tabular}{r|r|r|r|r}
\hline 110 & $\$ 619,819,000$ & $\$ 72,050$ & $\$ 475,107,000$ & $\$ 59,600$ \\
90 & $512,652,000$ & 59,600 & $388,315,000$ & 45,200 \\
70 & $418,377,000$ & 48,700 & $320,611,000$ & 37,300 \\
50 & $266,171,000$ & 30,900 & $185,769,000$ & 21,600 \\
\hline
\end{tabular}

Estimated Cost - Cape Henlopen

\begin{tabular}{r|r|r|r|r}
\hline 110 & $\$ 649,851,000$ & $\$ 75,800$ & $\$ 500,368,000$ & $\$ 62,800$ \\
90 & $537,769,000$ & 62,800 & $409,034,000$ & 47,900 \\
70 & $439,139,000$ & 51,400 & $338,083,000$ & 39,600 \\
50 & $280,117,000$ & 32,800 & $196,820,000$ & 23,200 \\
\hline
\end{tabular}

c. Cost Curves. Curves comparing unit costs for varying water depths are shown in Figure 22. Details of the estimate are given in Table 4.

\section{CONCLUSIONS}

Given the concept of a combination breakwater-oil storage system discussed in this study, the first consideration from a practical viewpoint is whether or not such a concept is feasible.

In view of the present knowledge and experience with open-sea construction problems, and of the development of construction equipment for 


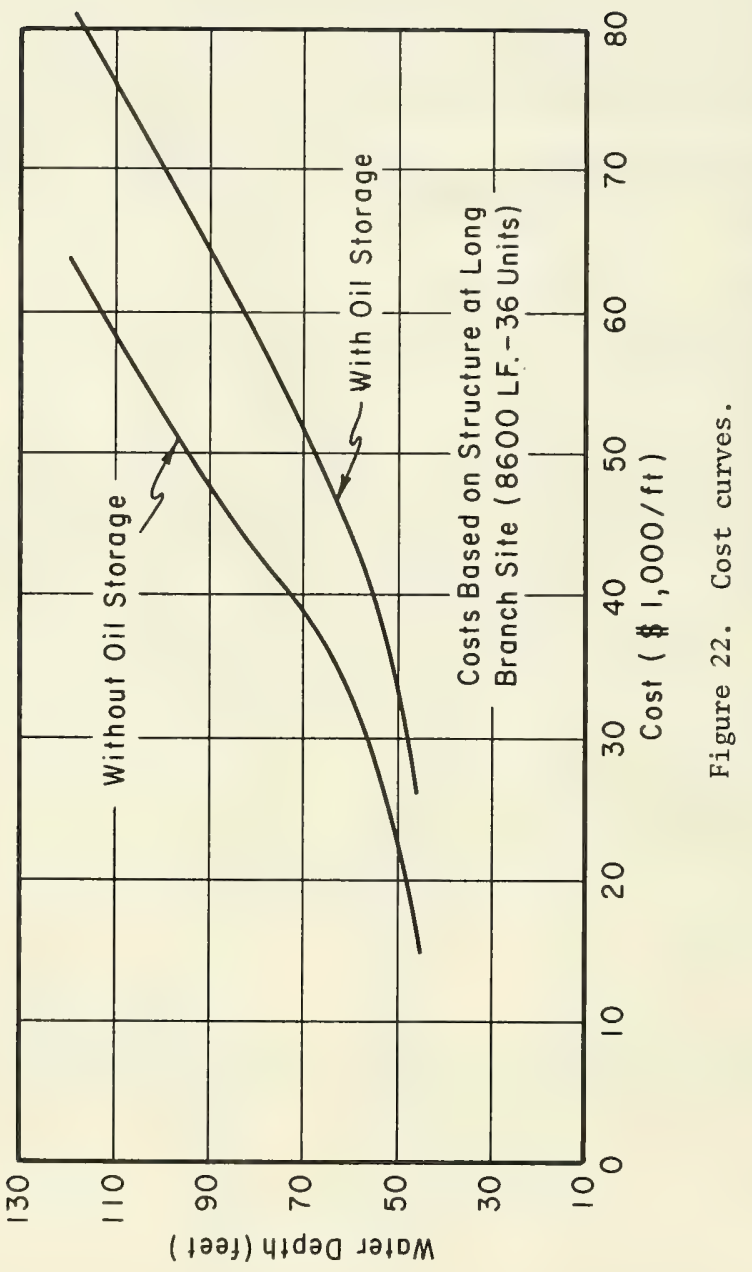




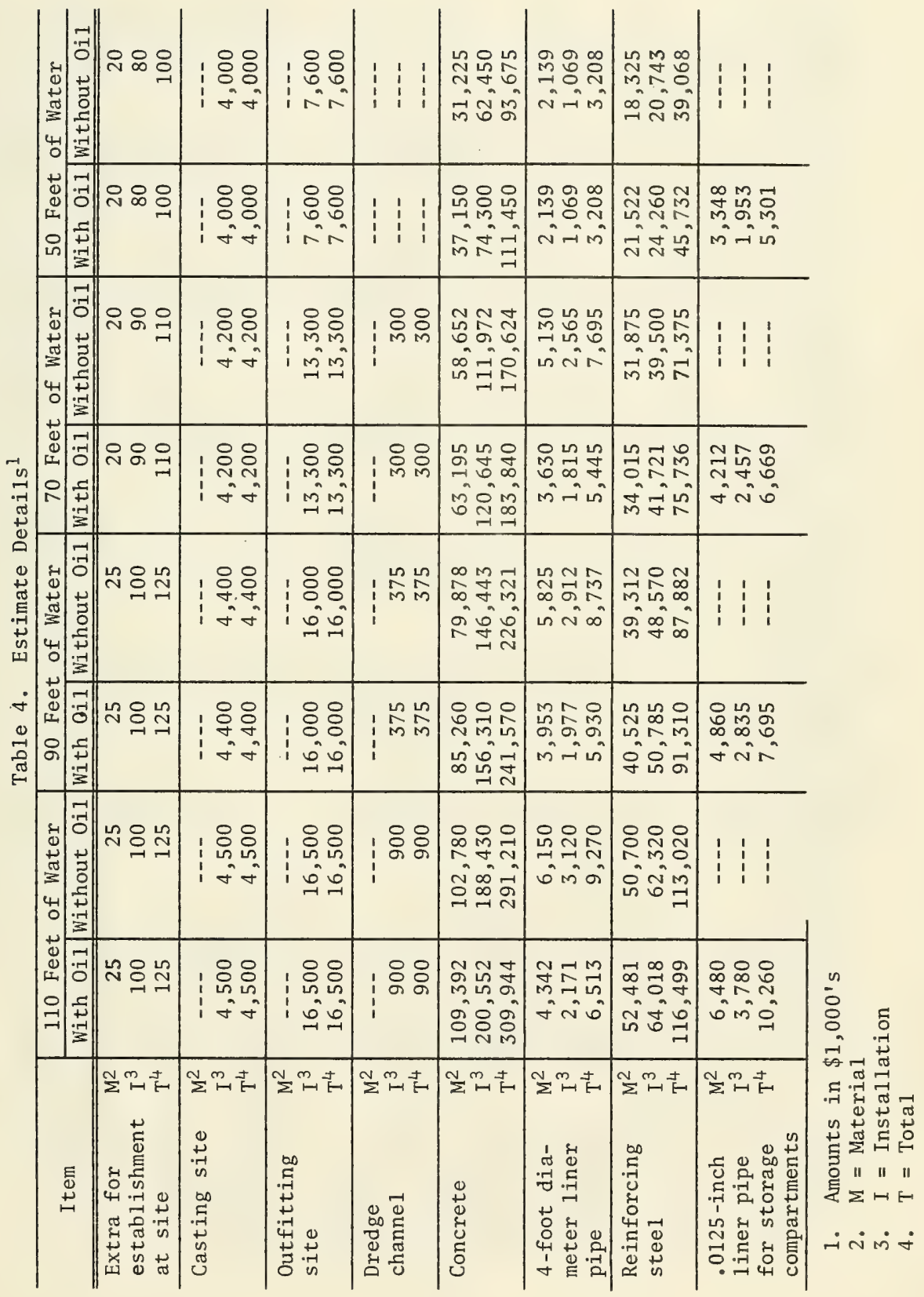




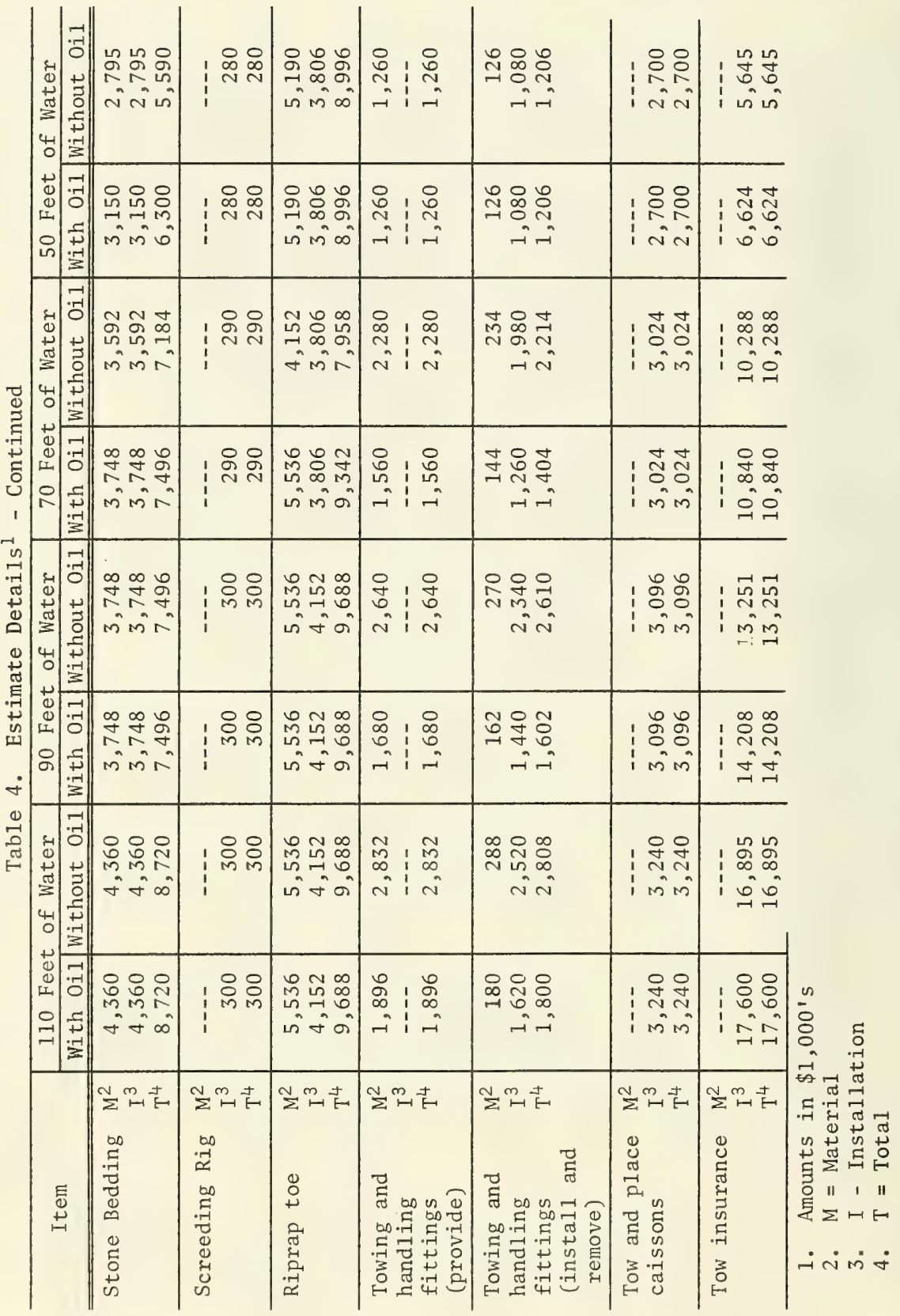




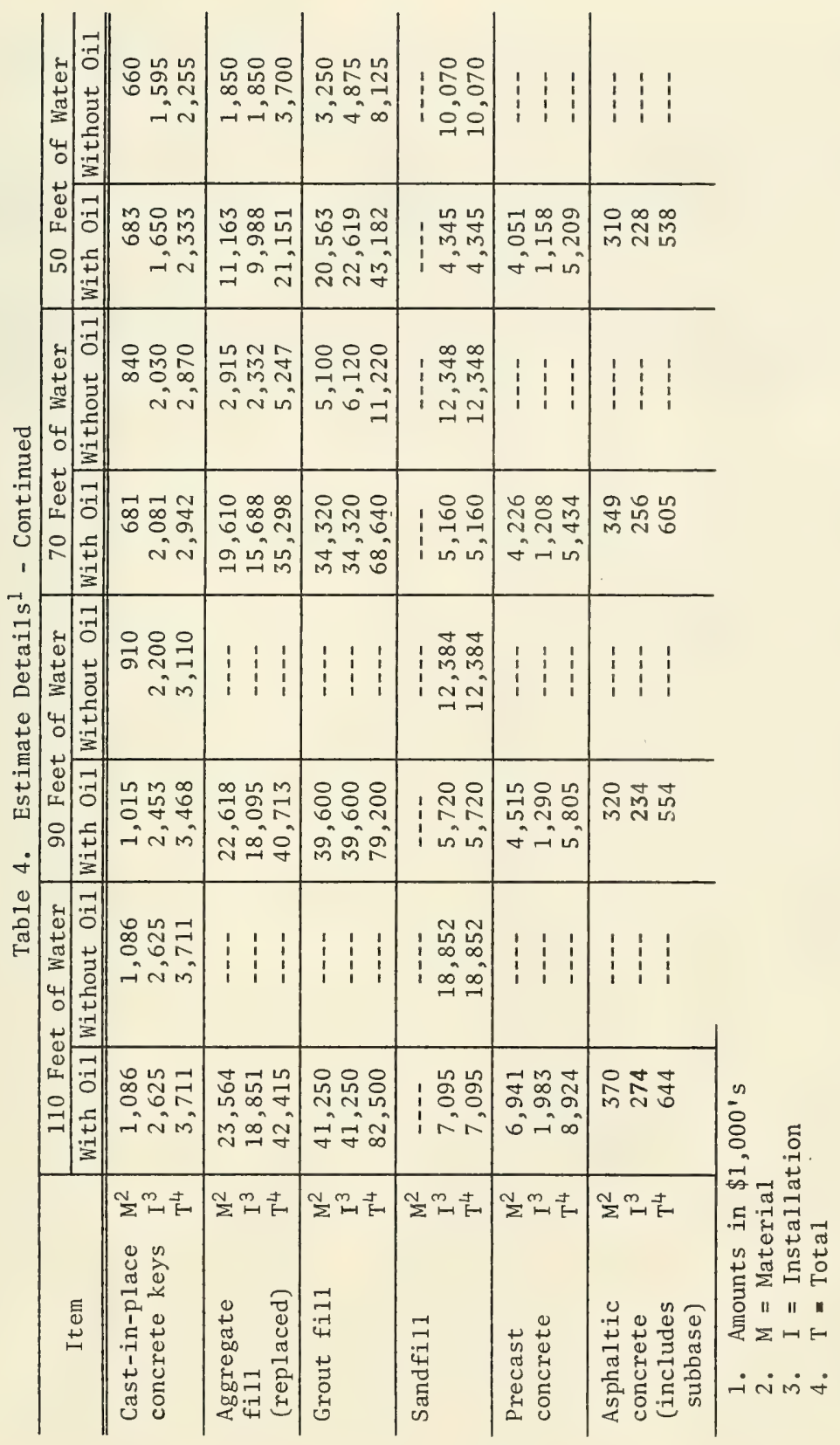




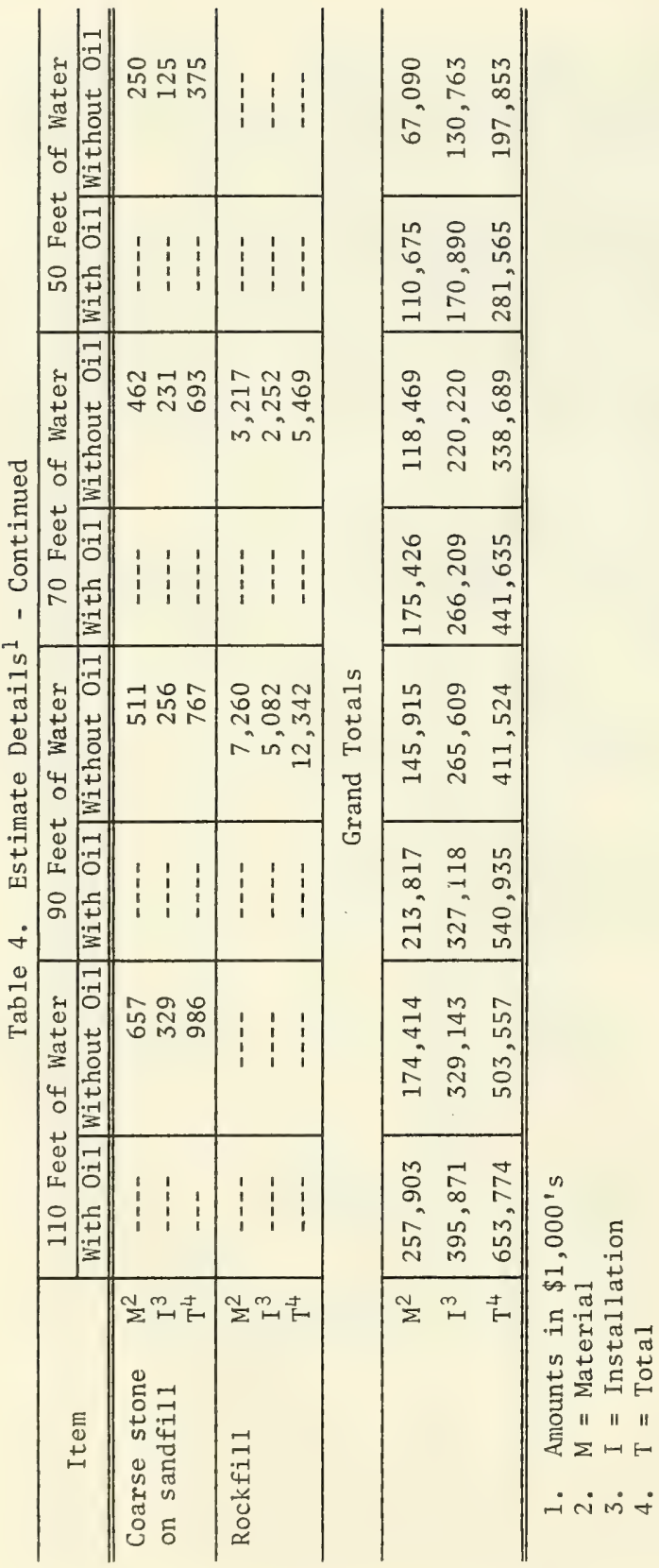


operating under such specialized conditions, the concept is entirely feasible and well within the capabilities of the construction industry.

Any site chosen for actual construction will differ from the site conditions assumed for this study. However, a conservative approach has been assumed in this study and the adjustments necessary to adapt to actual conditions at a specific site should be minor.

For a project of this magnitude, encompassing such variable conditions, model studies are a necessity. Size, conformation, and orientation of the breakwater and the general variables used in this study can be confirmed by model studies and adjustments made as necessary before starting final design efforts. 
JARLAN, G.E., "A Perforated Vertical Wall Breakwater," The Dock and Harbour Authority, Vo1. 41, No. 486, Apr. 1961, pp. 394-398.

MARKS, W., and JARLAN, G.E., "Experimental Studies on a Fixed Perforated Breakwater," Proceedings of the 11th Conference on Coastal Engineering, ASCE, Vol. II, 1969, pp. 1121-1140.

SAVILLE, T., Jr., "North Atlantic Coast Wave Statistics Hindcast by Bretschneider - Revised Sverdrup - Munk Method," TM-55, U.S. Army, Corps of Engineers, Beach Erosion Board, Washington, D.C., Nov. 1954.

UNIFORM BUILDING CODE, "Uniform Building Code Standards," International Conference of Building Officia1s, Vo1. 1, 1970 (listed in Appendix).

U.S. ARMY, CORPS OF ENGINEERS, COASTAL ENGINEERING RESEARCH CENTER, Shore Protection Planning and Design, TR-4, U.S. Government Printing Office, Washington, D.C., 1966, 572 pp.

U.S. ARMY, CORPS OF ENGINEERS, COASTAL ENGINEERING RESEARCH CENTER, Shore Protection Manual, Vols. I, II, and III, Stock No. 0822-00077, Ú.S. Government Printing Office, Washington, D.C., 1973, 1,160 pp.

U.S. NAVAL WEATHER SERVICE COMMAND, "Summary of Synoptic Meteorological Observations, North American Coastal Marine Areas," Vol. 3, Asheville, N.C., May 1970. 
APPENDIX

SAMPLE CALCULATIONS FOR DESIGN OF CONCRETE CAISSON 


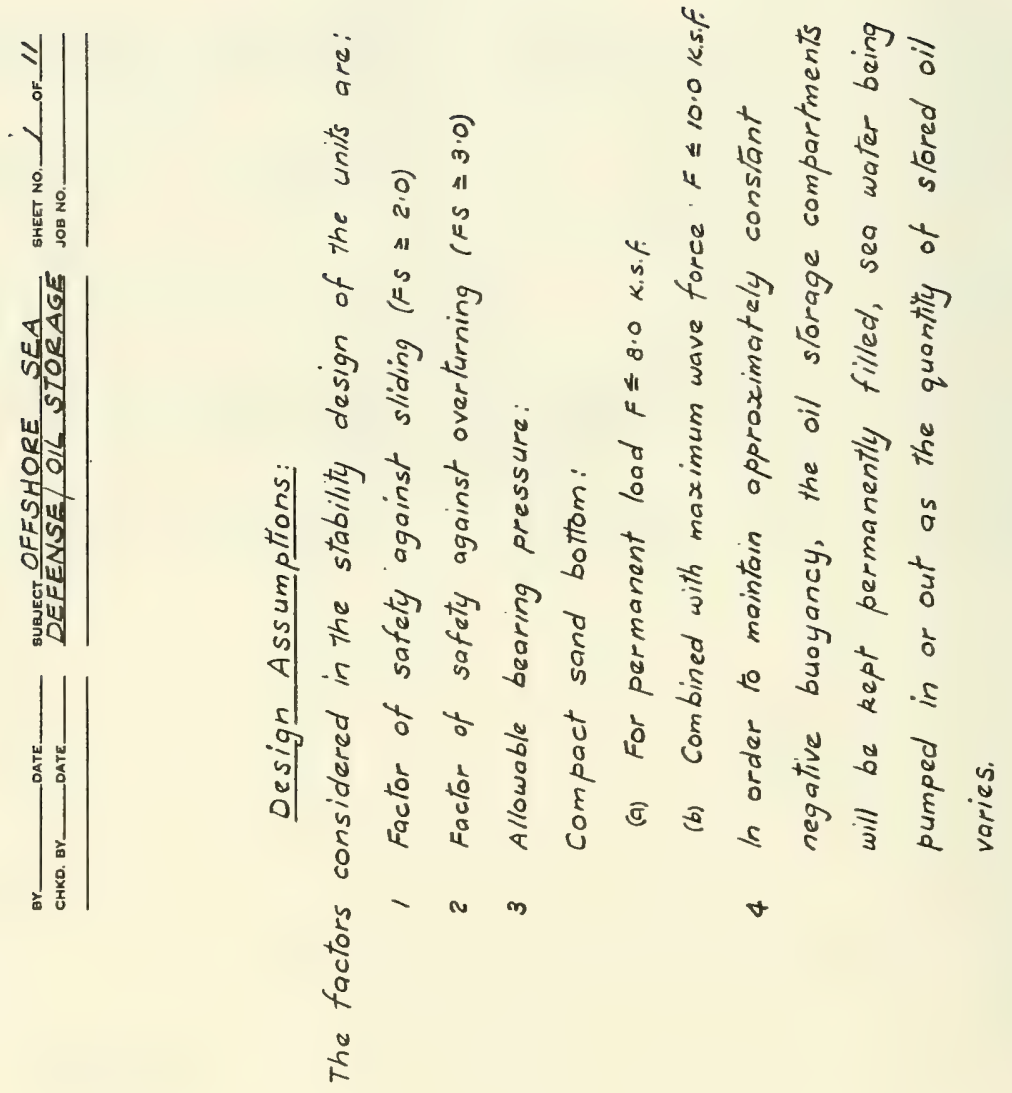



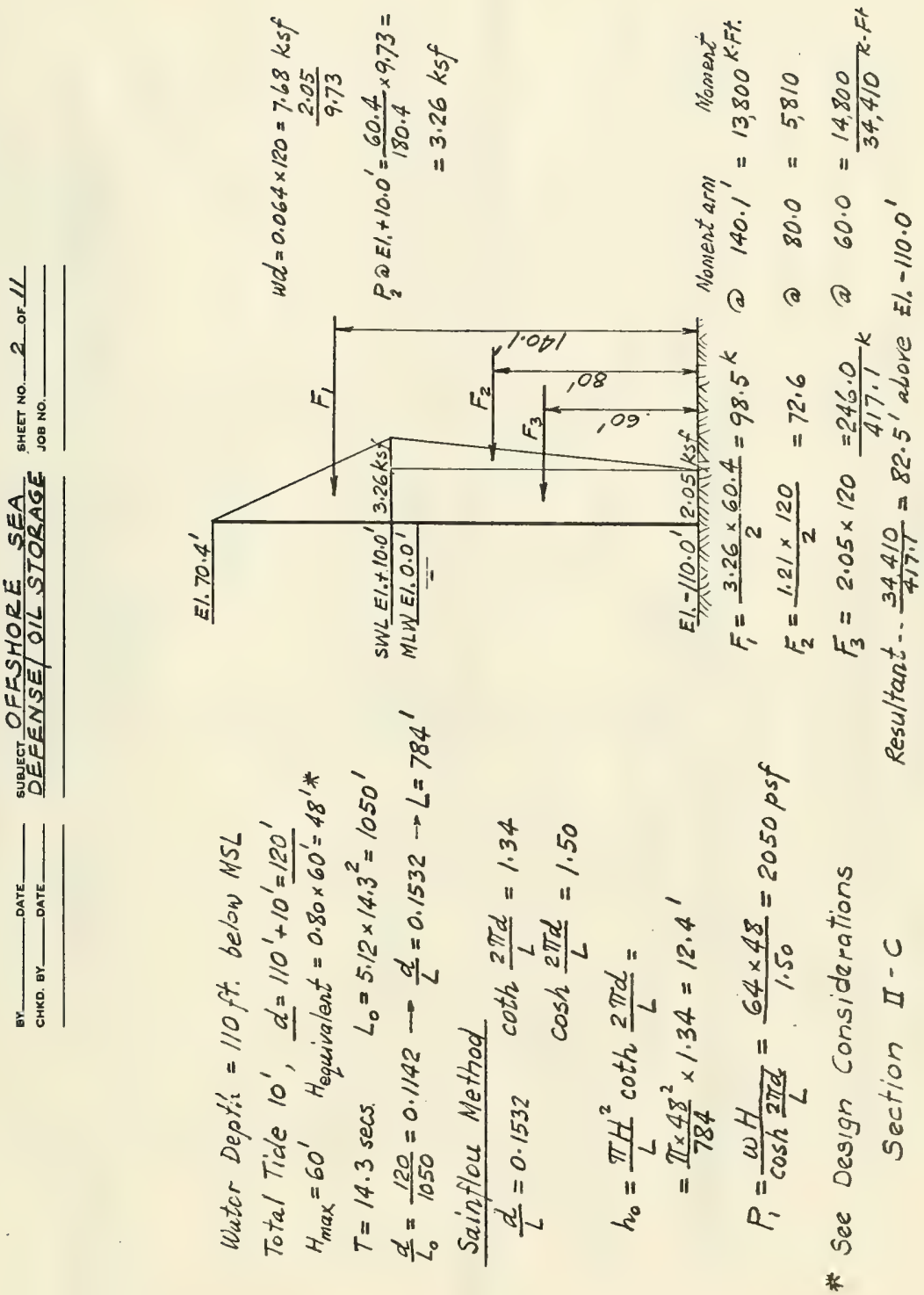


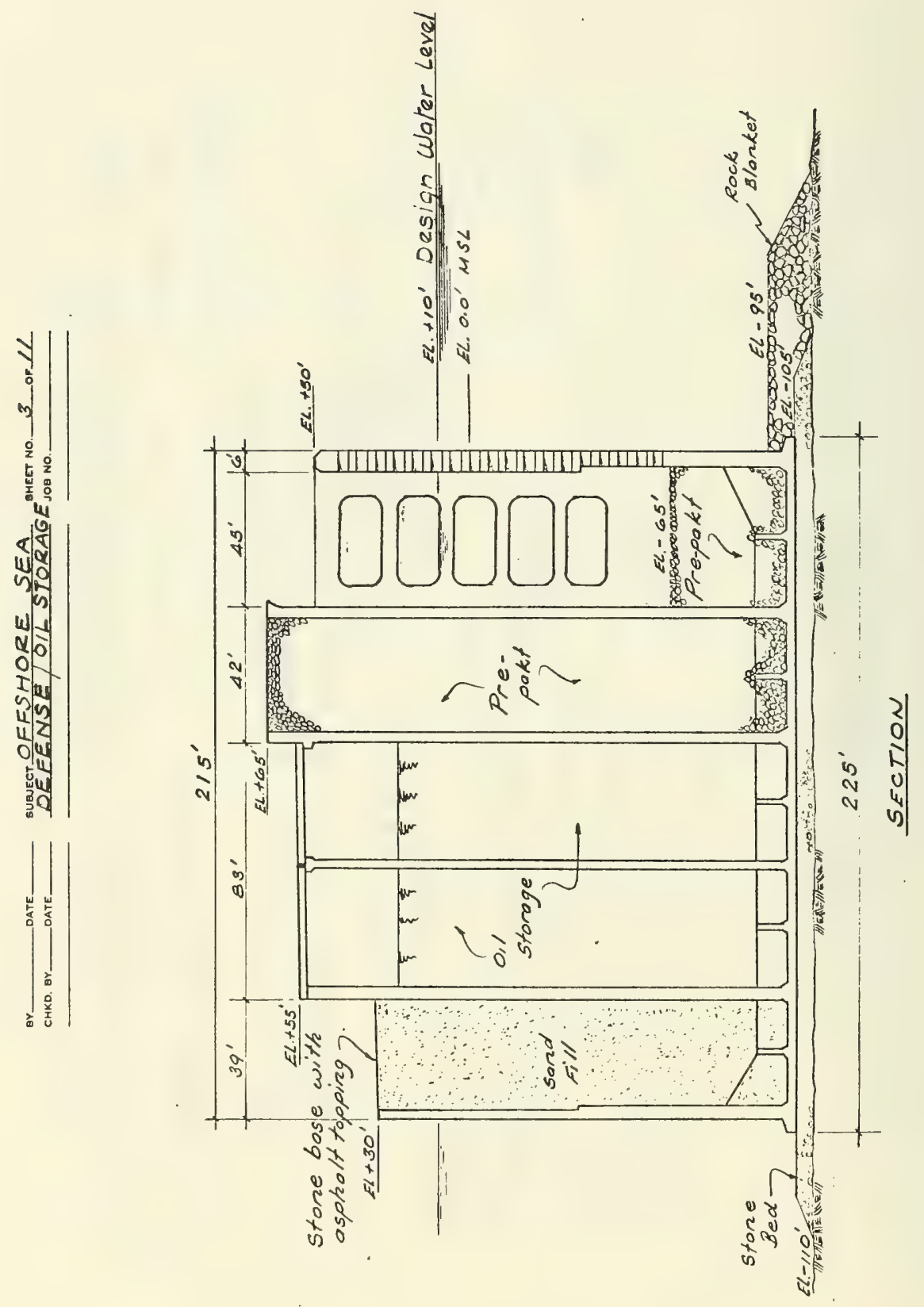




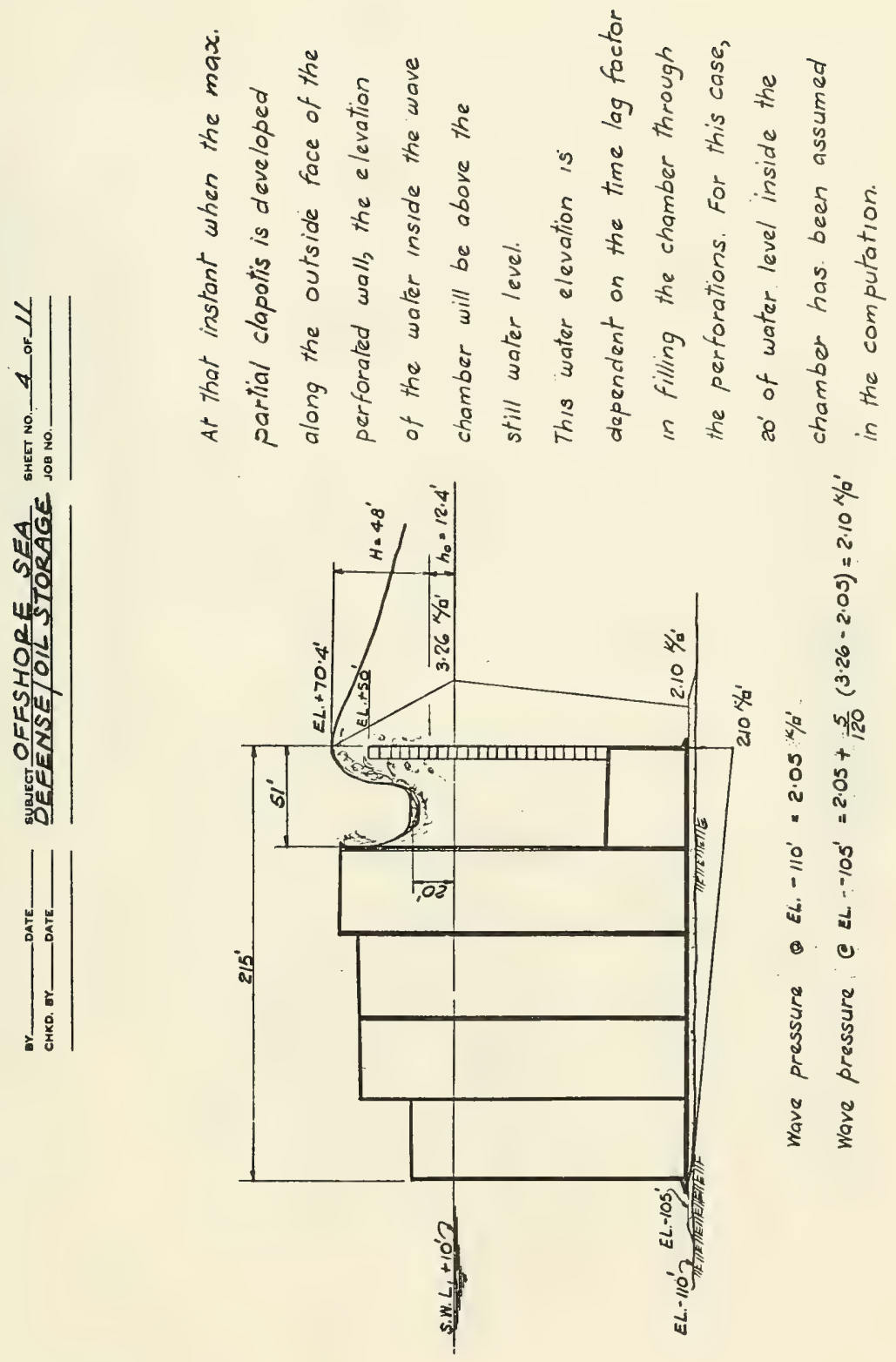



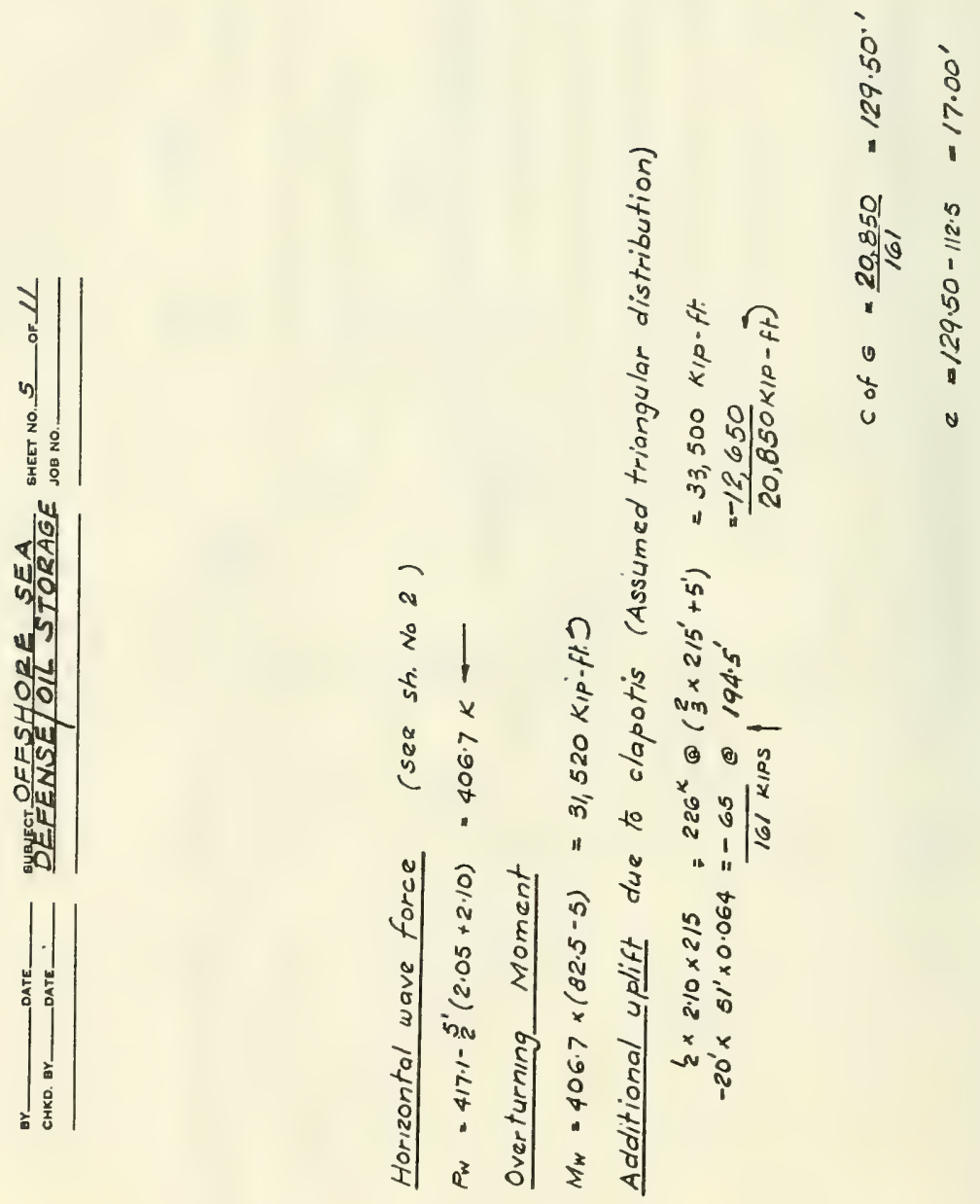

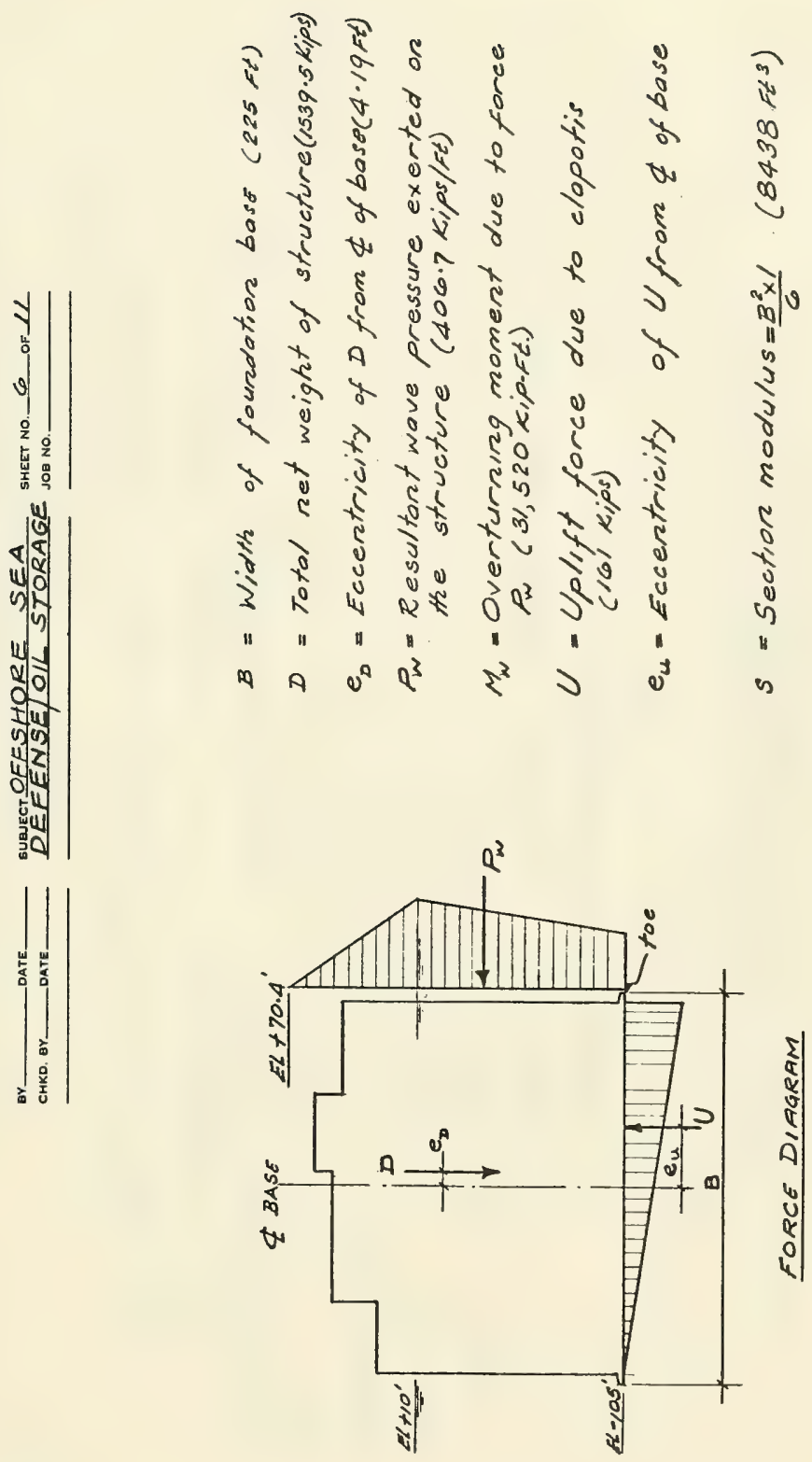

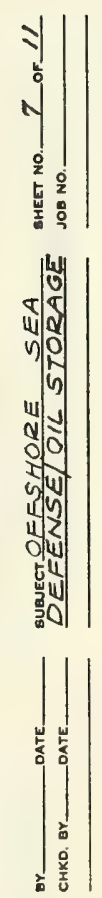

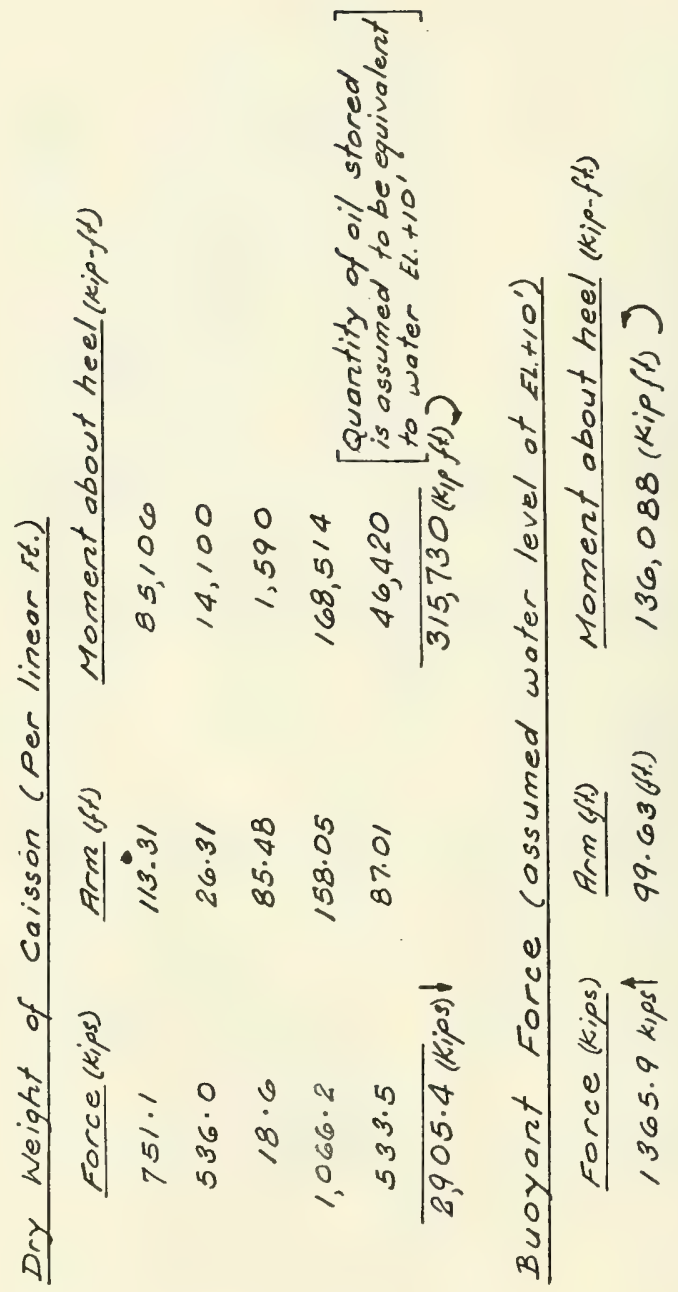

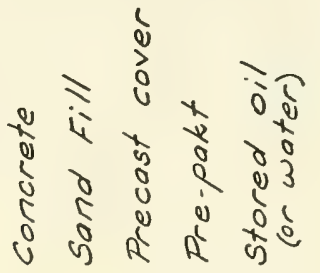



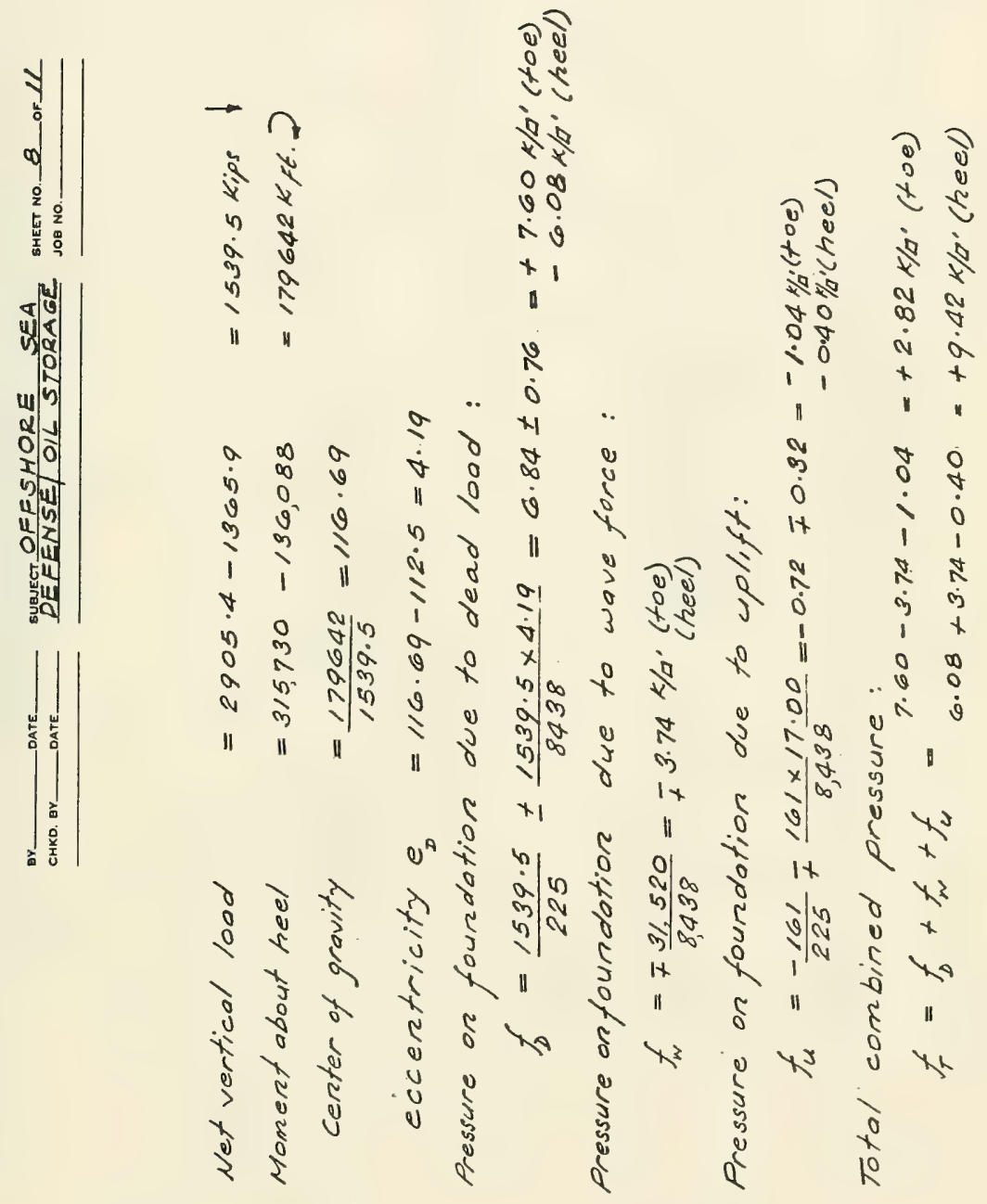

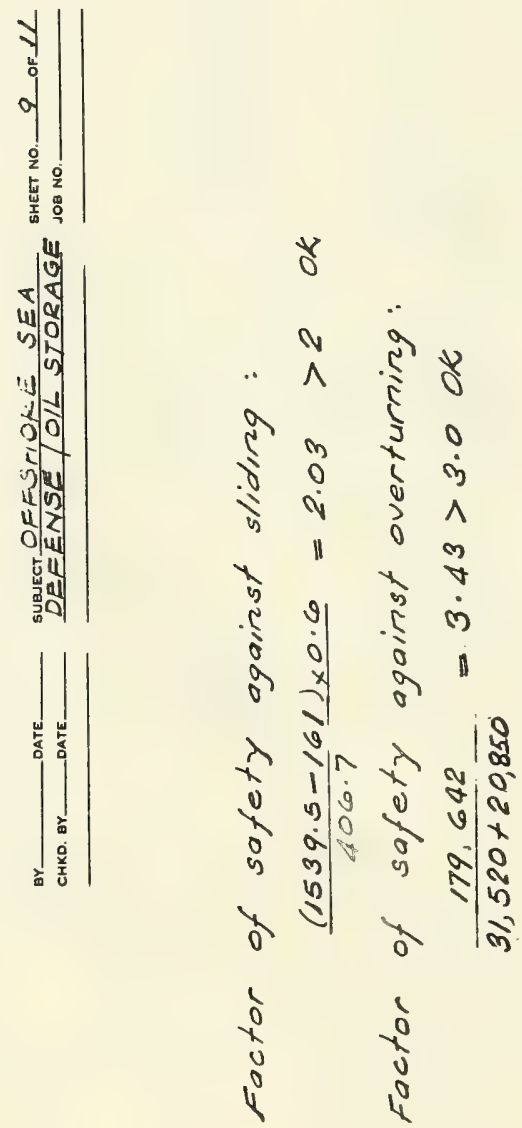


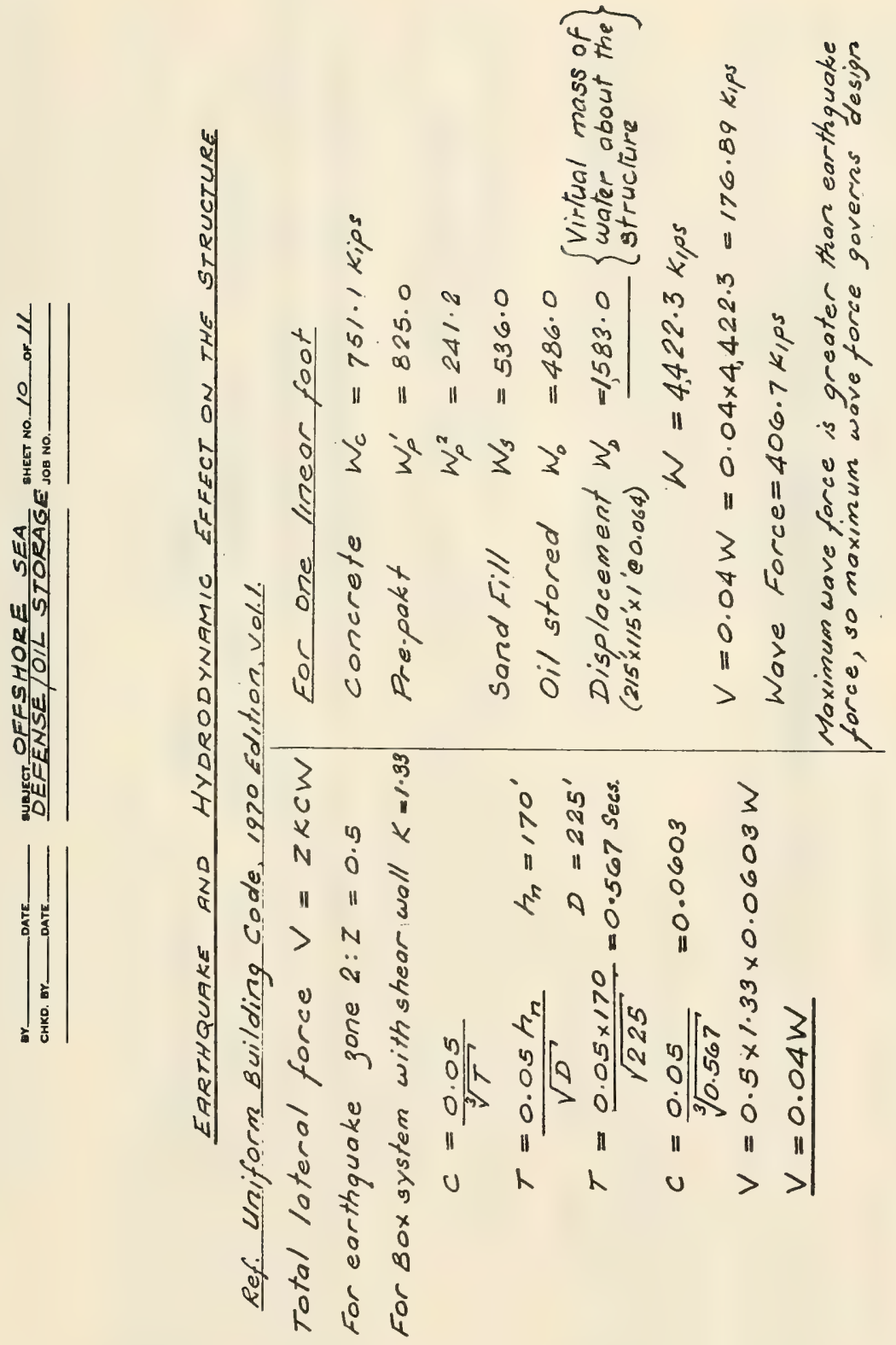




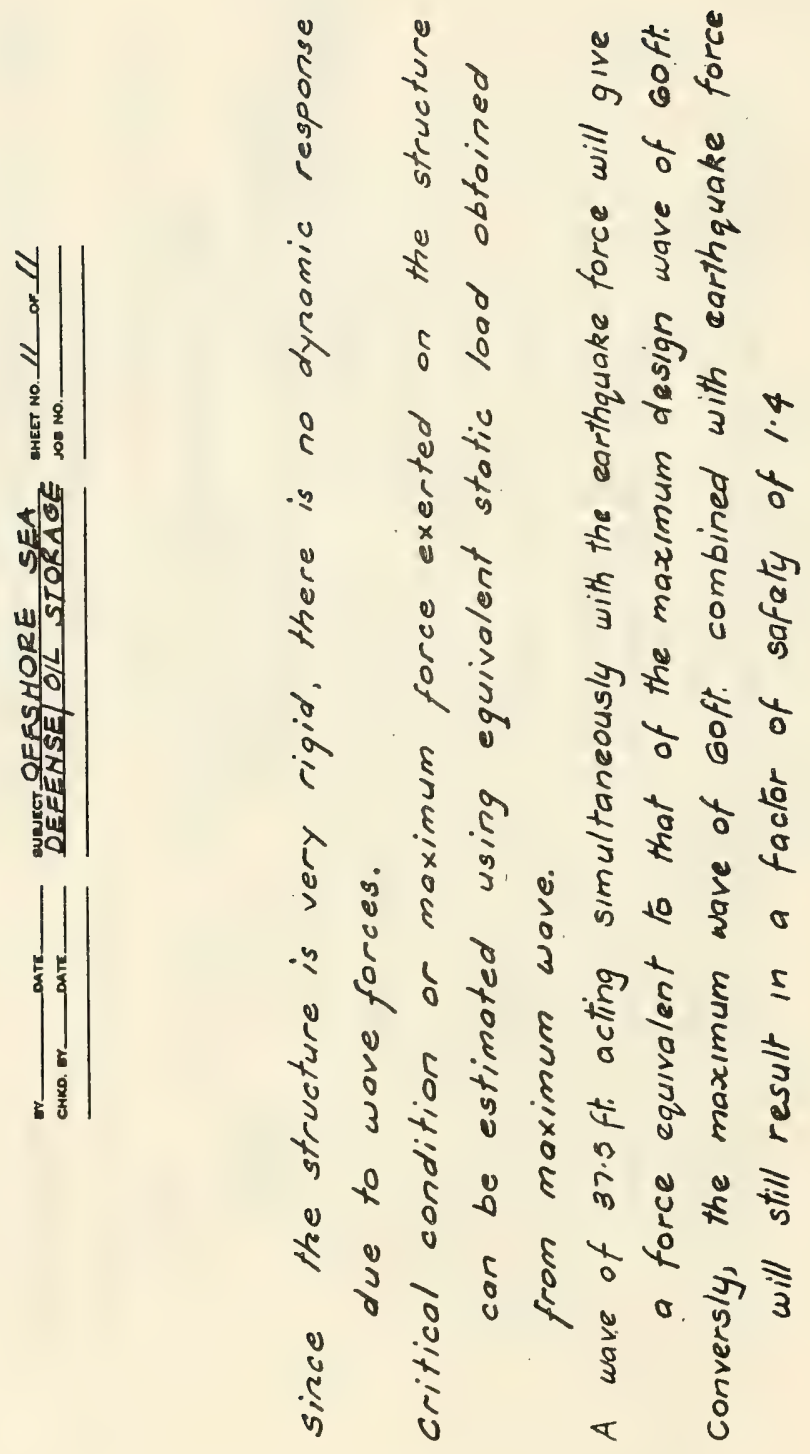




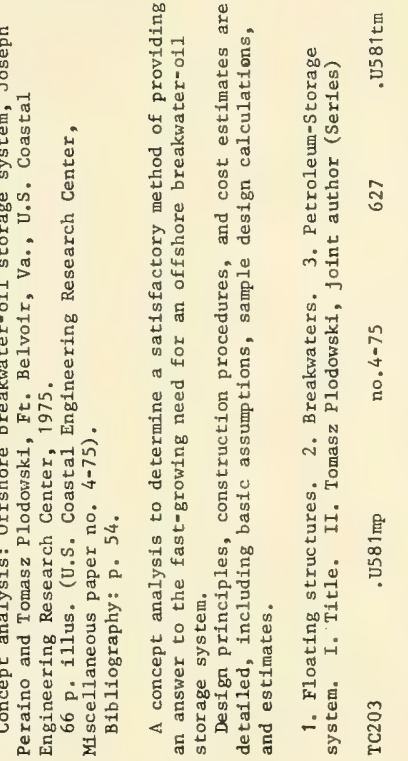

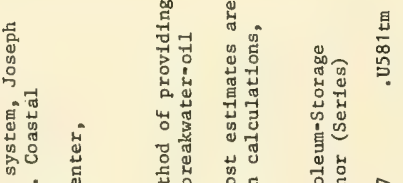

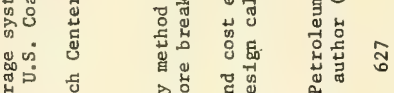

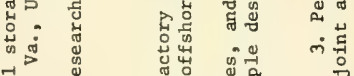

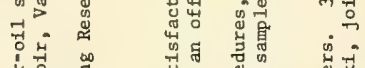

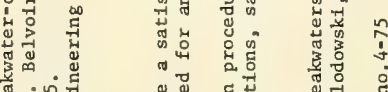

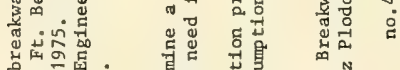

而

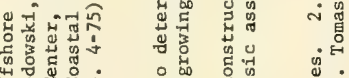

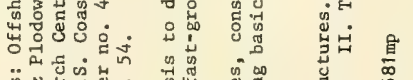

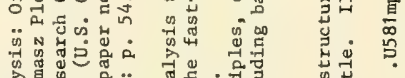

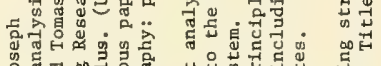

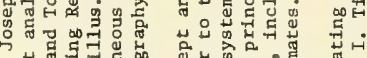

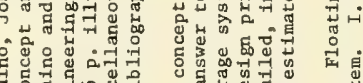

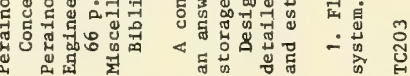

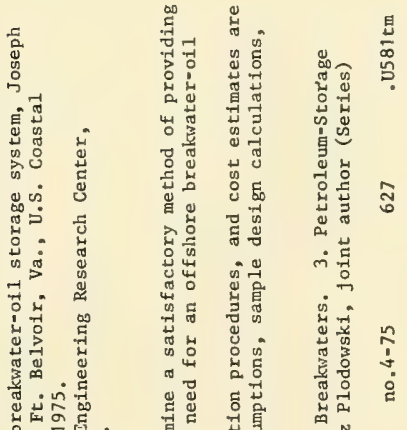

望

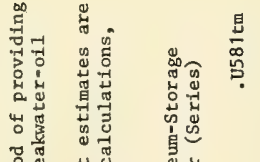

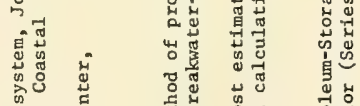

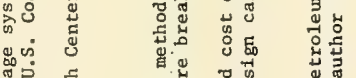

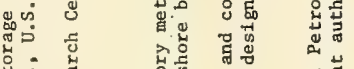

సิ

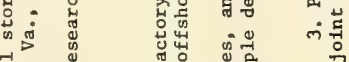

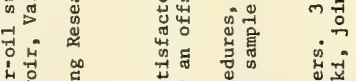

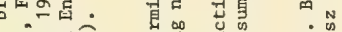

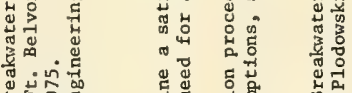

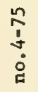

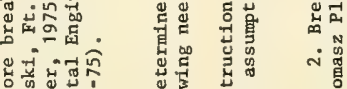

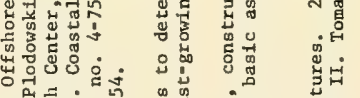

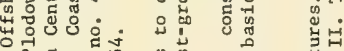

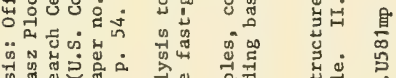

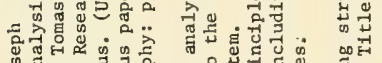

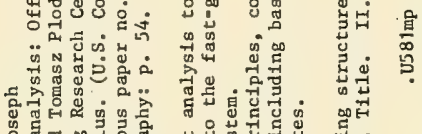

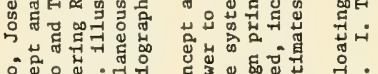

ถั

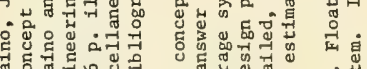

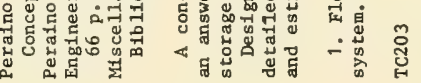





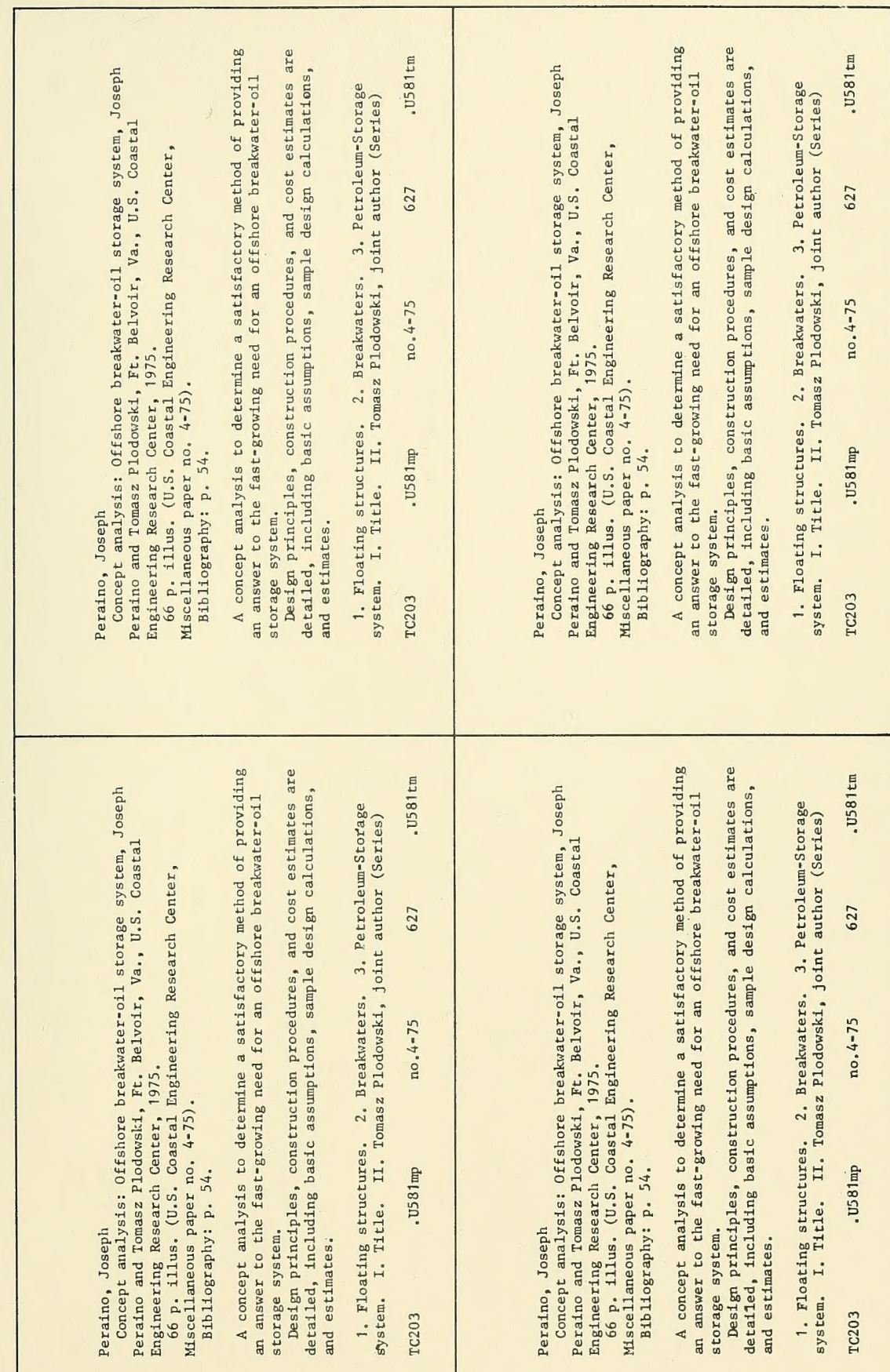



